\title{
Dissociation of multiple hydrogen molecules on the three- dimensional aluminium cluster: theoretical study
}

\author{
Jerzy Moc
}

Received: 31 December 2012/ Accepted: 17 June 2013/Published online: 3 July 2013

(C) The Author(s) 2013. This article is published with open access at Springerlink.com

\begin{abstract}
Compared to hydrogen activation on bare transition metal clusters, such reactions involving main group metal clusters have been less studied. Here, dissociative addition of multiple $\mathrm{H}_{2}$ to the group 13 metal cluster $\mathrm{Al}_{6}$ is investigated theoretically to examine the viability of generating $\mathrm{Al}_{6} \mathrm{H}_{8}$, the novel alane proposed experimentally by $\mathrm{Li}$ et al. Coupled-cluster $\operatorname{CCSD}(\mathrm{T})$ calculations with the aug-cc-pVTZ basis set are employed to determine the energetics of these additions, and density functional calculations are used to extensively probe the relevant potential energy surfaces. We find the sequential hydrogenations of $\mathrm{Al}_{6}$ via $\mathrm{Al}_{6} \mathrm{H}_{2 k-2}+\mathrm{H}_{2} \rightarrow \mathrm{Al}_{6} \mathrm{H}_{2 k}(k=1-4)$ exothermic, where the $\mathrm{Al}_{6} \mathrm{H}_{2 k}$ cluster global minima structures exhibit the same 'H-bridging motif' with two hydrogens sitting on the neighbouring threefold-bridged sites. Of various $\mathrm{H}_{2}$ dissociation modes probed including octahedral- and trigonal prism-like clusters, we find those involving dissociation transition states with the octahedrallike $\mathrm{Al}_{6}$ cores as kinetically most favoured. A correlation is identified between the $\mathrm{H}_{2}$ dissociation barriers and highest occupied molecular orbital-lowest unoccupied molecular orbital gaps of the $\mathrm{Al}_{6} \mathrm{H}_{2 k-2}$ clusters versus $k$. For $k=1$, the $\mathrm{H}_{2}$ dissociation is predicted to have no enthalpy barrier at the $\operatorname{CCSD}(\mathrm{T})$ /aug-cc-pVTZ level, and a good agreement is found between the coupled cluster and G4-calculated energetics. For $k=2,3$ and 4 , the lowest enthalpic hydrogen dissociation barriers are determined to be 12,14
\end{abstract}

Electronic supplementary material The online version of this article (doi:10.1007/s00214-013-1378-0) contains supplementary material, which is available to authorized users.

J. Moc $(\bowtie)$

Faculty of Chemistry, Wroclaw University, F. Joliot-Curie 14,

50-383 Wroclaw, Poland

e-mail: jerzy.moc@chem.uni.wroc.pl and $20 \mathrm{kcal} / \mathrm{mol}$, respectively, as measured relative to the $\mathrm{Al}_{6} \mathrm{H}_{2 k-2}$ cluster global minimum isomer plus $\mathrm{H}_{2}$ reactants. According to our calculations, the entropy contribution (-TS) to the free energy dissociation barrier is $8 \mathrm{kcal} / \mathrm{mol}$ per $\mathrm{H}_{2}$.

Keywords $\quad \mathrm{Al}_{6} \mathrm{H}_{2 k}$ alanes $(k=1-4) \cdot$ Multiple $\mathrm{H}_{2}$ dissociation on $\mathrm{Al}_{6}$. Octahedral- and trigonal prism-like transition states - Activation free energies $\cdot \operatorname{CCSD}(\mathrm{T}) /$ aug-cc-pVTZ

\section{Introduction}

Studying of adsorption/dissociation of molecular hydrogen on the surface of bare transition metal clusters has been an active research area and is well documented (see, e.g. [15]). The important rationale behind these studies is that gas-phase transition metal clusters have served model systems for catalysis [6]. By contrast, hydrogen activation by main group metal clusters has been investigated on a smaller scale. A recent experimental example is provided by the reaction of lithium atoms in solid $\mathrm{H}_{2}$ to form on annealing lithium hydride dimer $(\mathrm{LiH})_{2}$ [7]. Turning to the main group 13, nanosized aluminium-hydride clusters have recently attracted some attention because of their potential application as the hydrogen storage media [8]. Sub-nanosized $\mathrm{Al}_{13}$ cluster was investigated in that direction using density functional theory (DFT) with the aim of determining its hydrogen storage capacity $[9,10]$ and kinetic barrier for the dissociative chemisorption of hydrogen on its surface $[9,11]$.

The relevant gas-phase experimental study of the reactions of $\mathrm{Al}_{n}$ clusters $(n \leq 30)$ with deuterium molecules under mild conditions was conducted by Cox et al. [12]. In that study, which revealed a strong dependence of the 


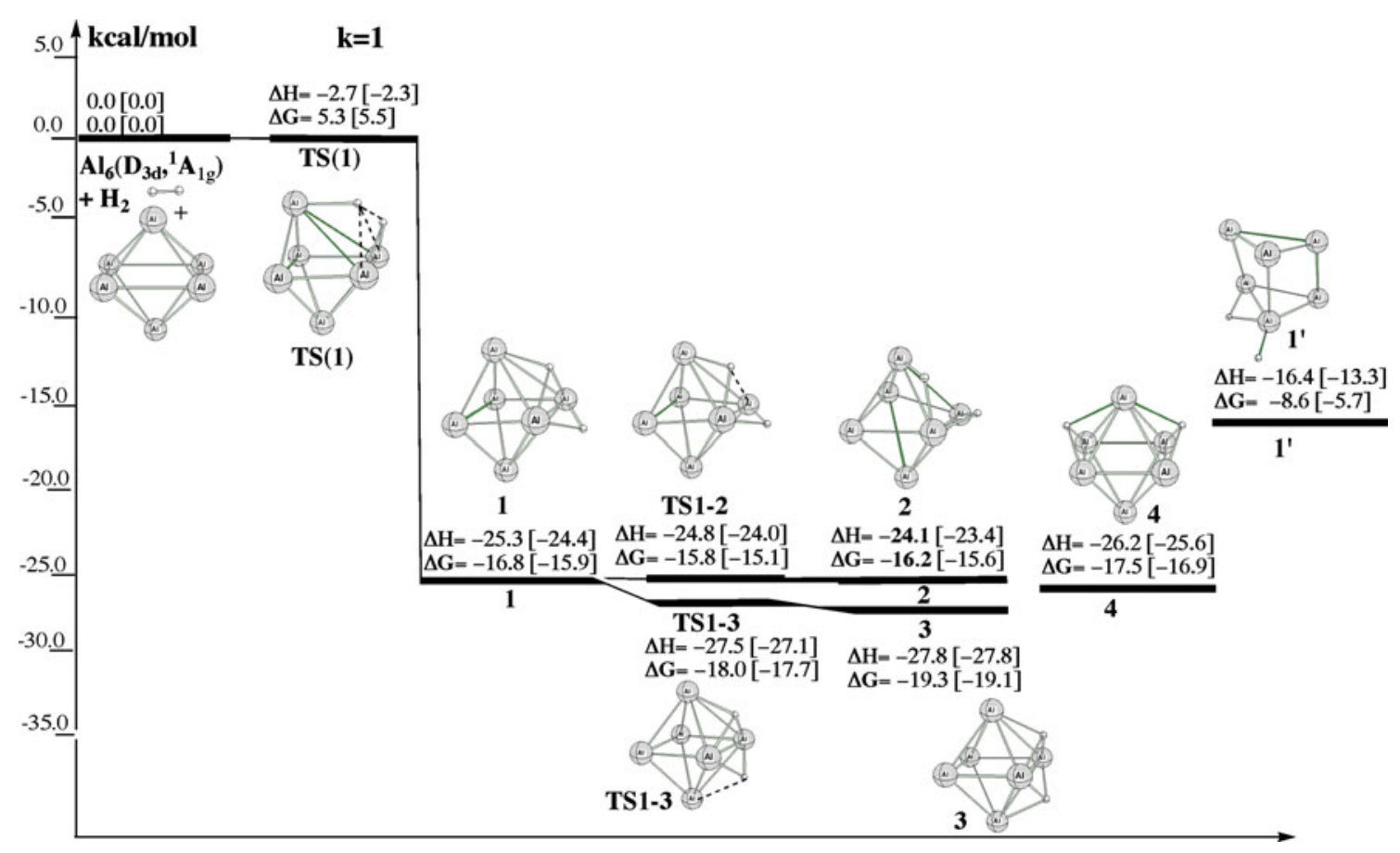

Fig. 1 Schematic enthalpy/free energy profiles (values in $\mathrm{kcal} / \mathrm{mol}$ ) for dissociation of $\mathrm{H}_{2}$ on singlet $\mathrm{Al}_{6}\left({ }^{1} \mathrm{~A}_{1 \mathrm{~g}}\right)$ calculated at the $\operatorname{CCSD}(\mathrm{T}) /$ aug-cc-pVTZ//B3LYP/aug-cc-pVTZ and G4 levels. The $\Delta H$ and

reactivity on cluster size, the largest relative rate constant was determined for $n=6$ (aluminium hexamer). The subsequent quantum chemical studies of the $\mathrm{Al}_{6}+\mathrm{H}_{2}$ reaction by Moc [13] and Pino et al. [14] were consistent with the experimental outcome [12]. Furthermore, the reported [13-17] theoretical studies of the $\mathrm{Al}_{n}+\mathrm{H}_{2}$ reactions with $n=2-6$ have demonstrated that $\mathrm{Al}_{6}$ behaves uniquely, if one judges the ability of the aluminium cluster in the ground electronic state to activate $\mathrm{H}_{2}$. Indeed, for the $\mathrm{H}_{2}$ addition to $\mathrm{Al}_{2}$ dimer $[14,15,17]$ and $\mathrm{Al}_{4}$ tetramer [14], whose ground electronic states are the triplets, the prior crossing between the triplet and singlet potential energy surfaces (PESs) is required along the reaction coordinate to reach the lower energy singlet energy surface of the $\mathrm{H}_{2}$ dissociation transition state and hydrogenation product. Also, the $\mathrm{H}_{2}$ addition to $\mathrm{Al}_{3}$ trimer [14, 16] and $\mathrm{Al}_{5}$ pentamer [14], whose ground electronic states are the doublets, present the reactions with significant energy barriers for hydrogen dissociation, unlikely accessible under mild conditions.

Recently, by using anion photoelectron spectroscopy (PE) combined with DFT calculations, Li et al. [18, 19] investigated novel $\mathrm{Al}_{n} \mathrm{H}_{m}^{-}$cluster anions $(4 \leq n \leq 8$, $0 \leq m \leq 10$ ) formed by the reactions of $\mathrm{Al}_{n}^{-}$with atomic hydrogen. By analysing the cluster anion PE spectra, it was recognized [19] that neutral clusters of formula $\mathrm{Al}_{n} \mathrm{H}_{n+2}$ $(5 \leq n \leq 8)$ had significantly large HOMO-LUMO gaps indicative of their increased stability. The following DFT pseudopotential study of Martinez and Alonso (ML) [20]
$\Delta G(T=298 \mathrm{~K})$ values shown are relative to the global minimum reactant asymptote $\mathrm{Al}_{6}\left({ }^{1} \mathrm{~A}_{1 \mathrm{~g}}\right)+\mathrm{H}_{2}$

Fig. 2 B3LYP/aug-cc-pVTZ and G4 optimized geometries (distances in $\AA$ ) of the transition state $\mathbf{T S}(\mathbf{1})$ (with the imaginary frequency) for dissociation of the hydrogen molecule on the singlet octahedral-like $\mathrm{Al}_{6}$ cluster to form doubly $\mathrm{H}$-bridged $\mathrm{Al}_{6} \mathrm{H}_{2}(\mathbf{1})$ cluster, along with the other di-bridged $\mathrm{Al}_{6} \mathrm{H}_{2}$ isomers (2-4) and transition states for their interconversion (TS1-2, TS1-3, with the imaginary frequencies) along with the prismatic-like isomer $\mathrm{Al}_{6} \mathrm{H}_{2}\left(\mathbf{1}^{\prime}\right)$; the $\mathrm{G} 4$ parameters are given within the square brackets. The B3LYP/aug-cc-pVTZ results are from [13]

using the PBE functional and plane wave basis set examined the structures, stability and bonding of the $\mathrm{Al}_{n} \mathrm{H}_{n+2}$ clusters $(n=4-11)$. In the related DFT work [21], similarities between the $\mathrm{Al}_{n} \mathrm{H}_{n+2}(n=4-12)$ alanes and corresponding boranes were traced, especially the question of to what extent the so-called Wade's rules could be applied to predict the alanes' ground state structures. We note, however, that mechanistic aspects of the hydrogenation of $\mathrm{Al}_{n}$ clusters leading to the $\mathrm{Al}_{n} \mathrm{H}_{n+2}$ alanes with $n \geq 6$ (via the $\mathrm{H}_{2}$ addition reactions), including the kinetic barriers, were not addressed so far.

In the current work, we extended our theoretical studies to explore the reactivity of $\mathrm{Al}_{6}$ hexamer towards multiple hydrogen molecules. Our work aims at identifying the lowenergy paths for the consecutive dissociative addition of $\mathrm{H}_{2}$ to the clusters $\mathrm{Al}_{6} \mathrm{H}_{2 k-2}$ to form the clusters $\mathrm{Al}_{6} \mathrm{H}_{2 k}$ with $k=1-4$. In particular, we investigated the viability of formation of $\mathrm{Al}_{6} \mathrm{H}_{8}$, considered the 'target' alane for the reasons given above. 


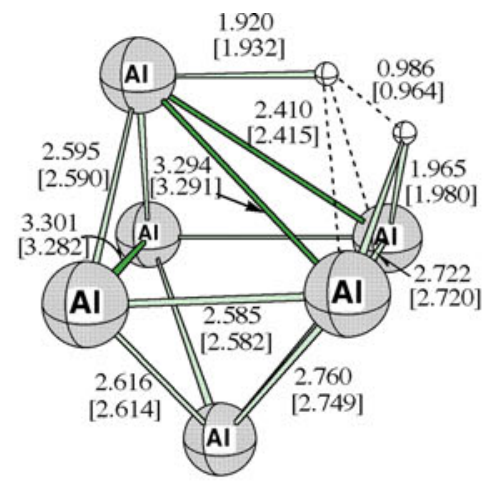

$\operatorname{TS}(1)\left(\mathrm{C}_{\mathrm{s}}\right)\left({ }^{1} \mathrm{~A}^{\prime}\right) 648[534] \mathrm{icm}^{-1}$

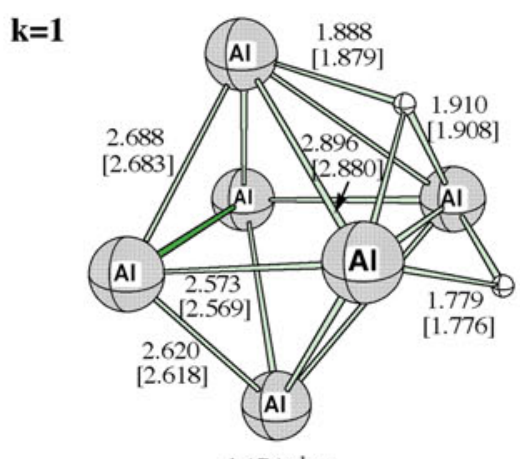

$1\left(\mathrm{C}_{\mathrm{s}}\right)\left({ }^{1} \mathrm{~A}^{\prime}\right)$
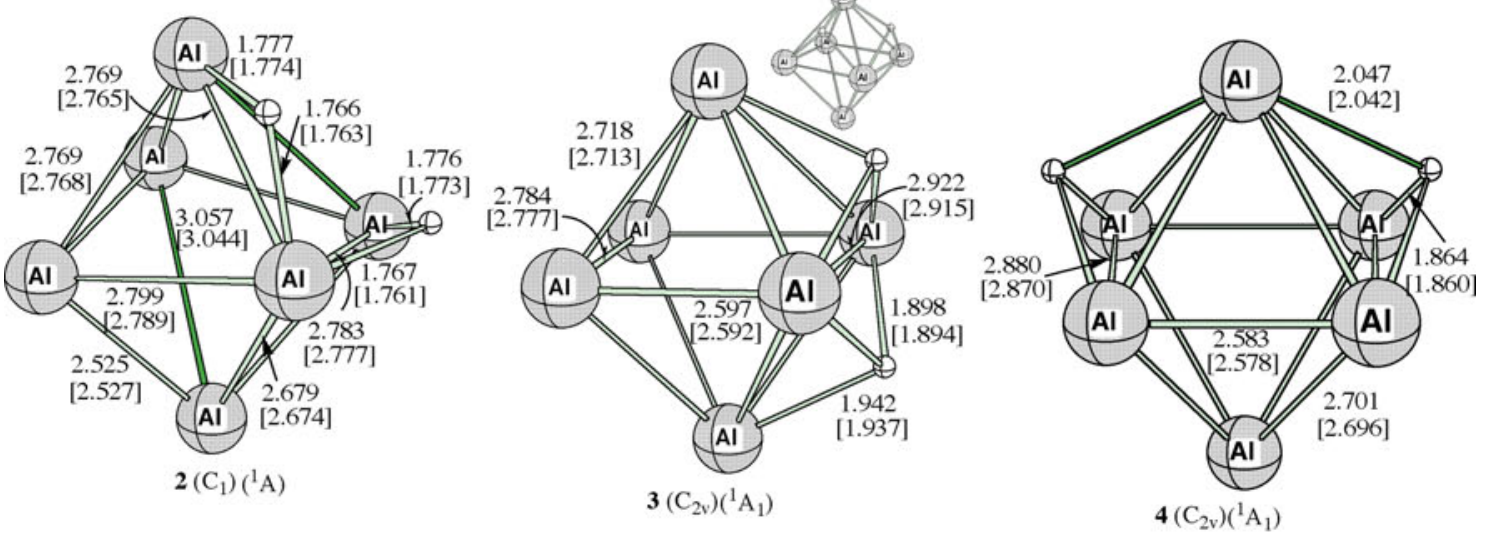

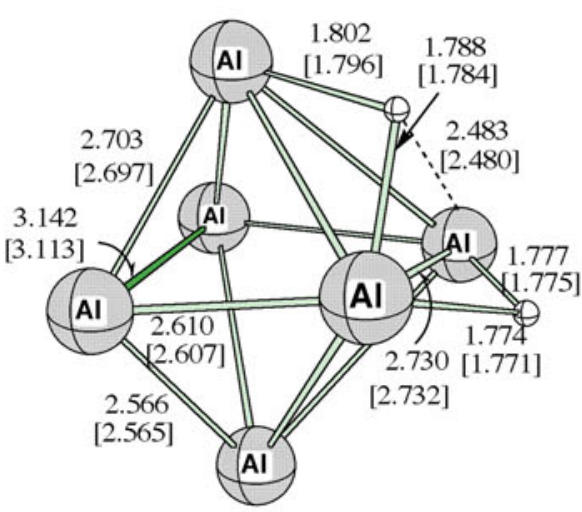

TS1-2 $\left(\mathrm{C}_{1}\right)\left({ }^{1} \mathrm{~A}\right) 159$ [159] $i \mathrm{~cm}^{-1}$

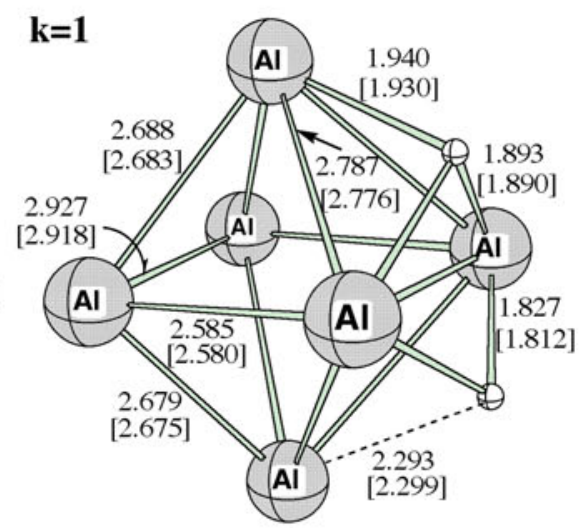

$\operatorname{TS} 1-3\left(\mathrm{C}_{\mathrm{s}}\right)\left({ }^{1} \mathrm{~A}^{\prime}\right) 180[188] i \mathrm{~cm}^{-1}$

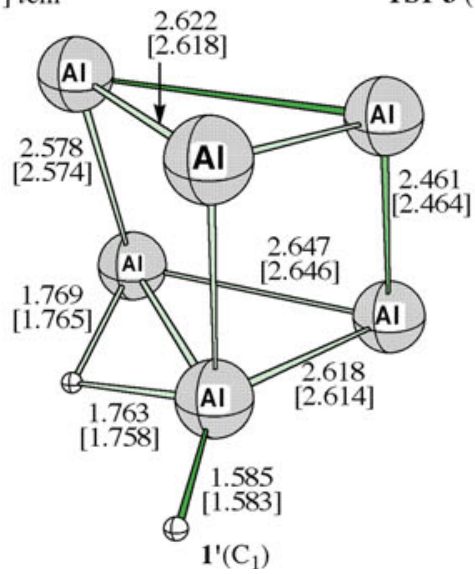




\section{Computational methods}

According to the most accurate and comprehensive theoretical studies reported $[14,22], \mathrm{Al}_{6}$ is the smallest aluminium cluster adopting a three-dimensional (3D) structure of lowest energy. To model adequately the reactions of multiple $\mathrm{H}_{2}$ addition to a 3D metal cluster in the gas phase, an extensive exploration of the underlying potential energy surfaces is crucial [5]. In search of the low-lying paths for $\mathrm{H}_{2}$ dissociation on the aluminium-hydride clusters, we have probed both the octahedron- and trigonal prism-like structures. The reason for this is that, for bare $\mathrm{Al}_{6}$, the octahedral and prism geometries lie close in energy [13, 14, 22].

The correlation-consistent aug-cc-pVTZ basis set [23] of triple-zeta quality was used throughout. All the geometries were optimized and characterized as minima or transition states using the B3LYP density functional [24, 25], where connectivity of the $\mathrm{H}_{2}$ dissociation transition states with the reactants and products was assured by calculating the intrinsic reaction coordinate [26]. The energetics of the $\mathrm{H}_{2}$ addition reactions was determined subsequently using the coupled-cluster singles-doublesperturbative triples $(\operatorname{CCSD}(\mathrm{T}))$ [27]. In addition to the relative energies, the enthalpy differences $(\Delta H)$ and the corresponding free energy differences $(\Delta G)$ (at $T=298 \mathrm{~K}$ ) have been determined at the latter level, where these thermodynamic values were obtained by including the zero-point energy, thermal and entropic corrections estimated with the help of the B3LYP/aug-cc-pVTZ vibrational frequencies. For testing purposes, the multilevel G4 scheme [28] was used as justified by the recent encouraging G4 versus coupled-cluster comparison for the predictions of reaction and activation energies [29, 30]. All the calculations were carried out with Gaussian 09 [31].

\section{Results and discussion}

Here, the low-lying paths for the consecutive $\mathrm{H}_{2}$ dissociations $\mathrm{Al}_{6} \mathrm{H}_{2 k-2}+\mathrm{H}_{2} \rightarrow \mathrm{Al}_{6} \mathrm{H}_{2 k}(k=1-4)$ are presented

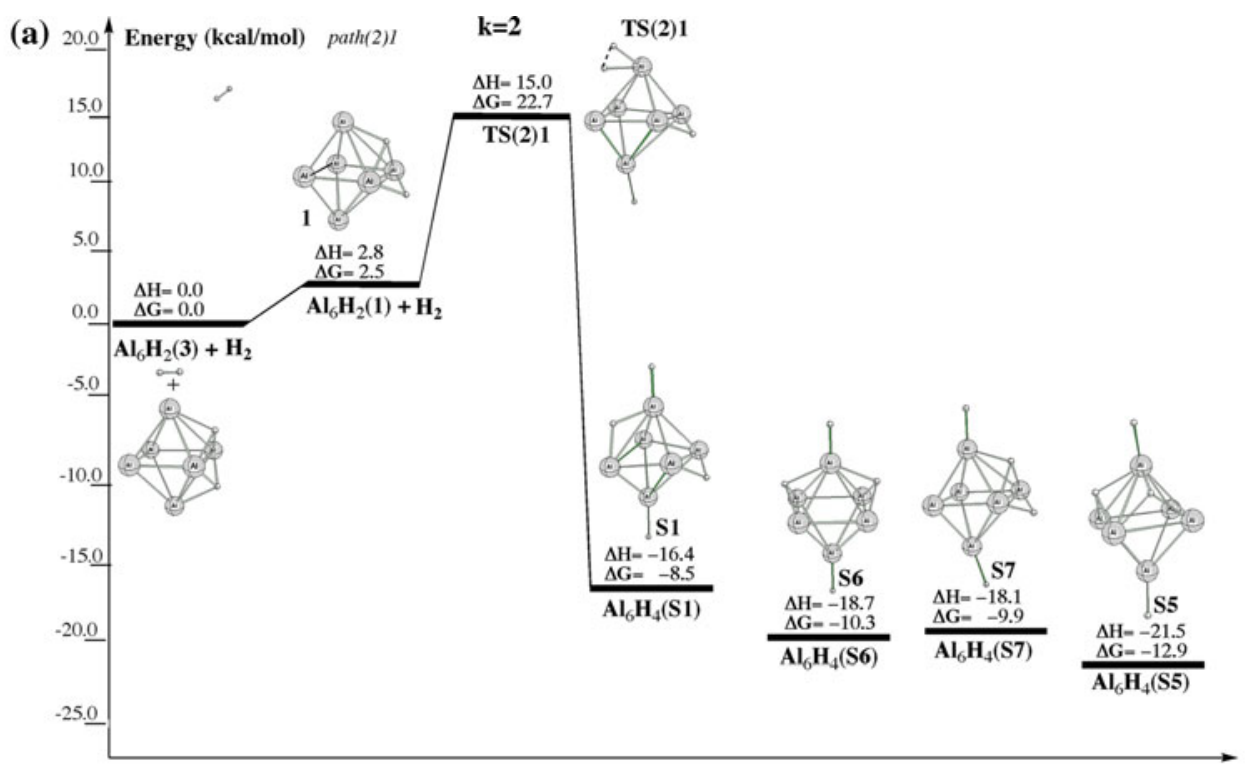

(b)

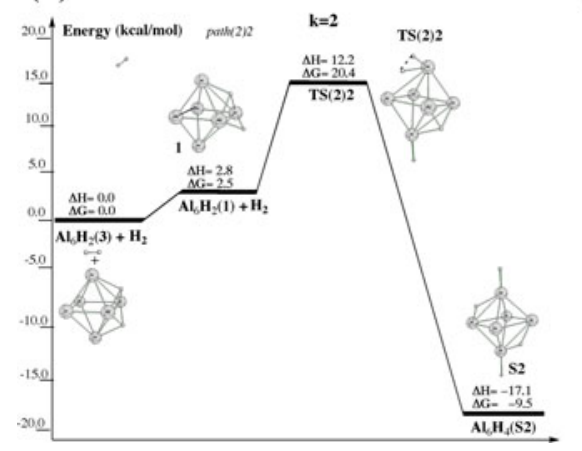

(c)

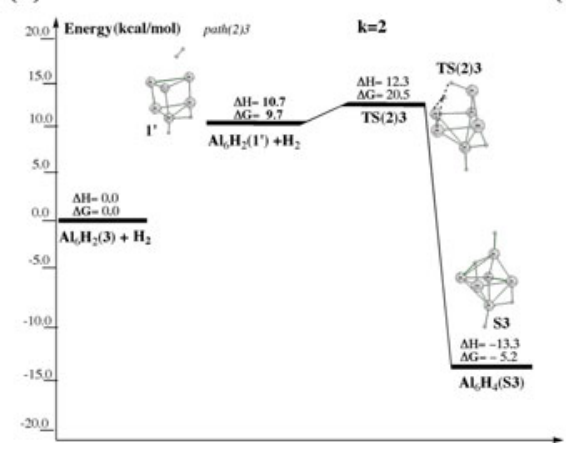

(d)

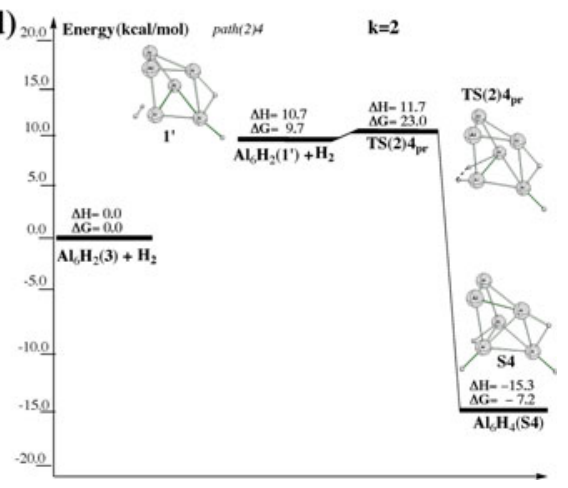

Fig. 3 Schematic enthalpy/free energy profiles (values in $\mathrm{kcal} / \mathrm{mol}$ ) for dissociation of $\mathrm{H}_{2}$ on $\mathrm{Al}_{6} \mathrm{H}_{2}$ calculated at the $\mathrm{CCSD}(\mathrm{T}) / \mathrm{aug}$-ccpVTZ//B3LYP/aug-cc-pVTZ level for the a path(2)1, b path(2)2, c path(2)3 and d path(2)4. The $\Delta H$ and $\Delta G(T=298 \mathrm{~K})$ values shown are relative to the global minimum reactant asymptote $\mathrm{Al}_{6} \mathrm{H}_{2}(3)+\mathrm{H}_{2}$ 


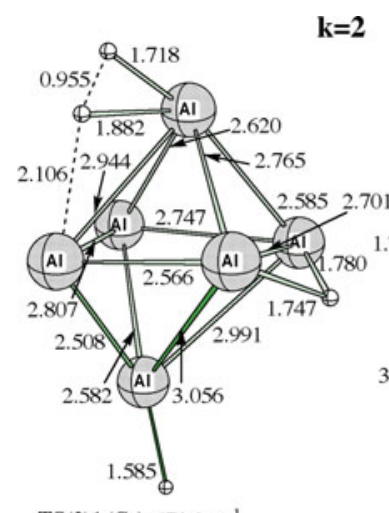

$\operatorname{TS}(\mathbf{2}) \mathbf{1}\left(\mathrm{C}_{1}\right) 471 i \mathrm{~cm}^{-1}$

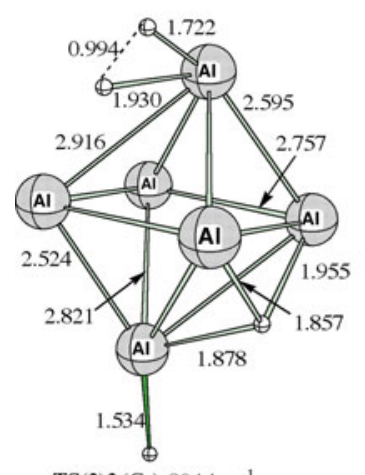

$\operatorname{TS}(\mathbf{2}) 2\left(\mathrm{C}_{1}\right) 804 \mathrm{icm}^{-1}$

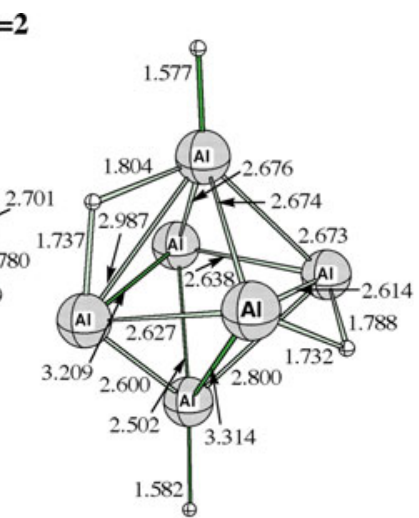

S1 $\left(\mathrm{C}_{1}\right)$

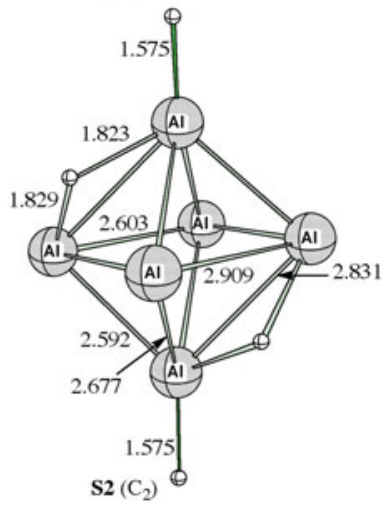

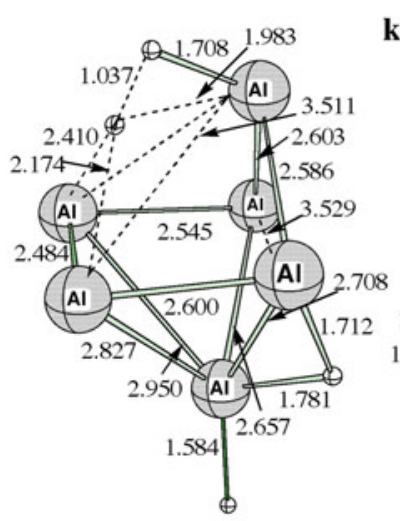

$\operatorname{TS}(\mathbf{2}) \mathbf{3}\left(\mathrm{C}_{1}\right) 942 \mathrm{icm}^{-1}$

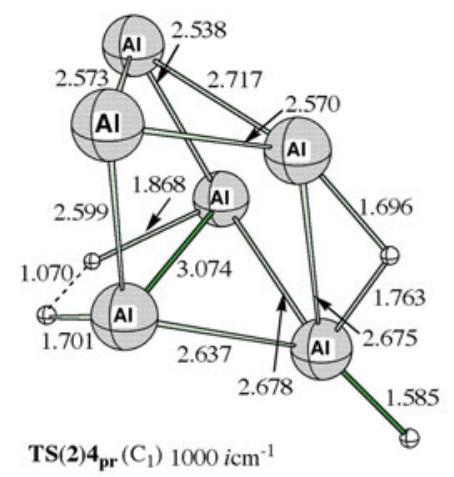

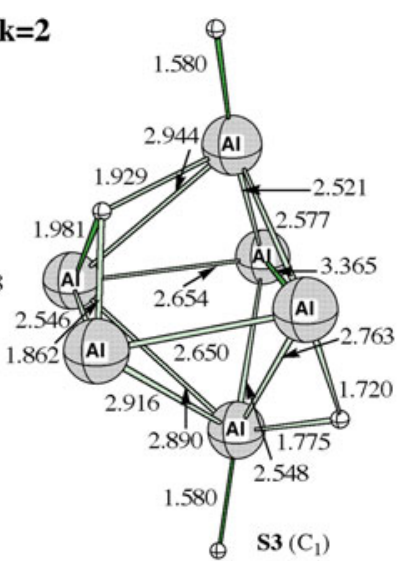

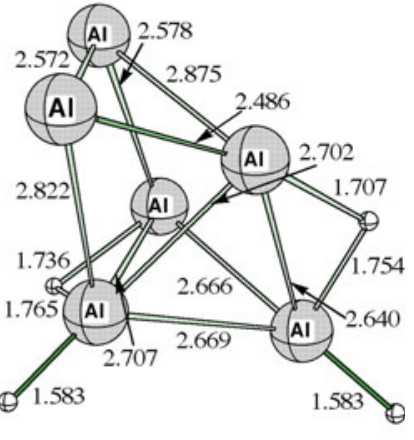

S4 $\left(\mathrm{C}_{1}\right)$

Fig. 4 Optimized geometries (B3LYP/aug-cc-pVTZ, distances in $\AA$ ) of the octahedral-TS(2)1, TS(2)2 and TS(2)3 and prismatic-like TS(2)4 transition states (with the imaginary frequencies) for dissociation of $\mathrm{H}_{2}$ on $\mathrm{Al}_{6} \mathrm{H}_{2}$ to yield $\mathrm{Al}_{6} \mathrm{H}_{4}$ clusters $\mathbf{S 1}, \mathbf{S 2}$, $\mathbf{S 3}$ and $\mathbf{S 4}$, respectively

Fig. 5 Optimized geometries (B3LYP/aug-cc-pVTZ, distances in $\AA$ ) of the lowenergy $\mathrm{Al}_{6} \mathrm{H}_{4}$ isomers S5-S7, including the global minimum $\mathrm{Al}_{6} \mathrm{H}_{4}$ structure $($ S5)
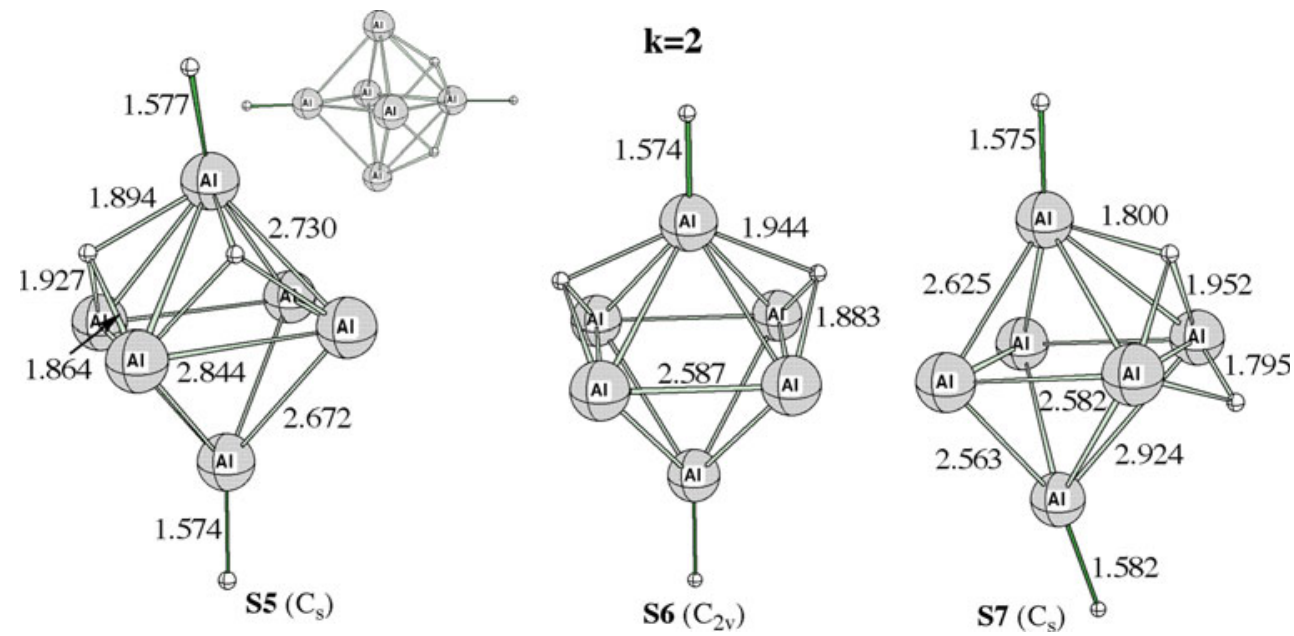

and discussed. The path of the $\mathrm{Al}_{6}+\mathrm{H}_{2} \rightarrow \mathrm{Al}_{6} \mathrm{H}_{2}$ reaction $(k=1)$ has been examined before [13, 14], but we summarize and 'extend' it in the next sub-section. The bulk of this report is devoted to the reaction steps with $k=2-4$, not investigated so far. The transition states involved in the dissociation of the second (S), third (T) and fourth (F) $\mathrm{H}_{2}$ are labelled $\mathbf{T S}(\mathbf{2}) \mathbf{j}, \mathbf{T S}(\mathbf{3}) \mathbf{j}$ and $\mathbf{T S}(\mathbf{4}) \mathbf{j}$, respectively, where $\mathbf{j}=1,2,3, \ldots$, indicate the TS number, with the ensuing hydrogenated clusters $\mathrm{Al}_{6} \mathrm{H}_{2 k}$ termed $\mathbf{S j}\left(\mathrm{Al}_{6} \mathrm{H}_{4}\right), \mathbf{T j}$
$\left(\mathrm{Al}_{6} \mathrm{H}_{6}\right)$ and $\mathbf{F j}\left(\mathrm{Al}_{6} \mathrm{H}_{8}\right)$. The prismatic-like transition states are differentiated from the octahedral-like ones by adding the subscript 'pr'.

\section{$3.1 k=1$}

Previously [13], we found the singlet state distorted octahedron $\mathrm{Al}_{6}\left(\mathrm{D}_{3 \mathrm{~d}},{ }^{1} \mathrm{~A}_{1 \mathrm{~g}}\right)$ to be this metal cluster lowest energy structure at the CCSD(T)/aug-cc-pVTZ//B3LYP/aug-cc- 


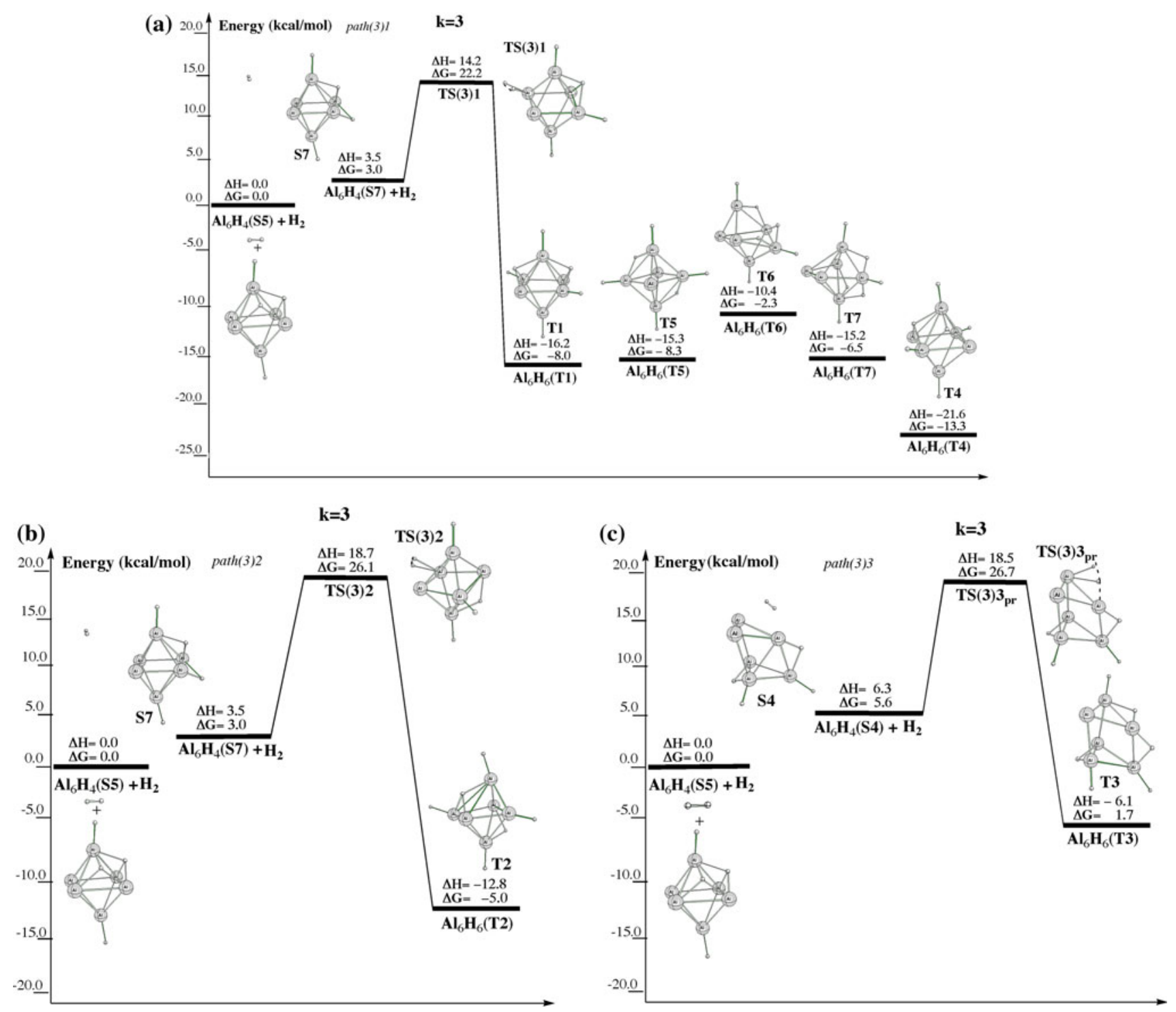

Fig. 6 Schematic enthalpy/free energy profiles (values in $\mathrm{kcal} / \mathrm{mol}$ ) for dissociation of $\mathrm{H}_{2}$ on $\mathrm{Al}_{6} \mathrm{H}_{4}$ calculated at the $\mathrm{CCSD}(\mathrm{T}) /$ aug-ccpVTZ//B3LYP/aug-cc-pVTZ level for the a path(3)1, b path(3)2 and

c path(3)3. The $\Delta H$ and $\Delta G(T=298 \mathrm{~K})$ values shown are relative to the global minimum reactant asymptote $\mathrm{Al}_{6} \mathrm{H}_{4}(\mathbf{S 5})+\mathrm{H}_{2}$

pVTZ level, the result confirmed recently by the $\operatorname{CCSD}(\mathrm{T})$ geometry optimization of $\mathrm{Al}_{6}$ by Pino [14] (at the B3LYP level, the lowest energy $\mathrm{Al}_{6}$ is the triplet $\left({ }^{3} \mathrm{~A}_{1}^{\prime}\right)$ trigonal prismatic $\left(\mathrm{D}_{3 \mathrm{~h}}\right)$ structure). The $\operatorname{CCSD}(\mathrm{T}) /$ aug-ccpVTZ//B3LYP/aug-cc-pVTZ energy profile of $\mathrm{H}_{2}$ dissociation on singlet $\mathrm{Al}_{6}$ is depicted in Fig. 1. The kinetically most favoured path obtained from the B3LYP calculations $[13,14]$ involves the singlet transition state $\mathbf{T S}(\mathbf{1})$ (see Fig. 2). The $\mathrm{H}_{2}$ dissociation on the singlet $\mathrm{Al}_{6}$ is kinetically favoured (in terms of the energy barrier) due to the favourable interaction of one of the two degenerate highest occupied molecular orbitals of $\mathrm{e}_{\mathrm{g}}$ symmetry of $\mathrm{Al}_{6}$ with the unoccupied molecular orbital $\sigma_{u}^{*}$ of $\mathrm{H}_{2}$ [14]. On the B3LYP PES, the TS(1) rearranges to the $\mathrm{Al}_{6} \mathrm{H}_{2}$ hydride $\mathbf{1}$, where one $\mathrm{H}$ atom is threefold bridged and the other $\mathrm{H}$ atom is twofold bridged (Fig. 2).

At the geometry optimization B3LYP level, there is a tiny energy barrier to $\mathrm{H}_{2}$ dissociation on singlet $\mathrm{Al}_{6}$ with respect to the $\mathrm{Al}_{6}\left({ }^{3} \mathrm{~A}_{1}^{\prime}\right)+\mathrm{H}_{2}\left({ }^{1} \Sigma_{g}^{+}\right)$system of $1.7 \mathrm{kcal} / \mathrm{mol}$ [14] and $0.3 \mathrm{kcal} / \mathrm{mol}$ using the $6-311+G^{*}$ and aug-ccpVTZ basis sets, respectively. At the $\operatorname{CCSD(T)/aug-cc-~}$ pVTZ//B3LYP/aug-cc-pVTZ level [13], the TS(1) energy drops below the correct $\mathrm{Al}_{6}\left({ }^{1} \mathrm{~A}_{1 \mathrm{~g}}\right)+\mathrm{H}_{2}\left({ }^{1} \Sigma_{g}^{+}\right)$asymptote, and therefore, no enthalpy barrier is found for $\mathrm{H}_{2}$ dissociation (Fig. 1). This suggests that TS(1) may not be a true transition state on the PES at the ab initio correlated level. The free energy barrier of $5.3 \mathrm{kcal} / \mathrm{mol}$ (Fig. 1) is due to the entropic contribution. 

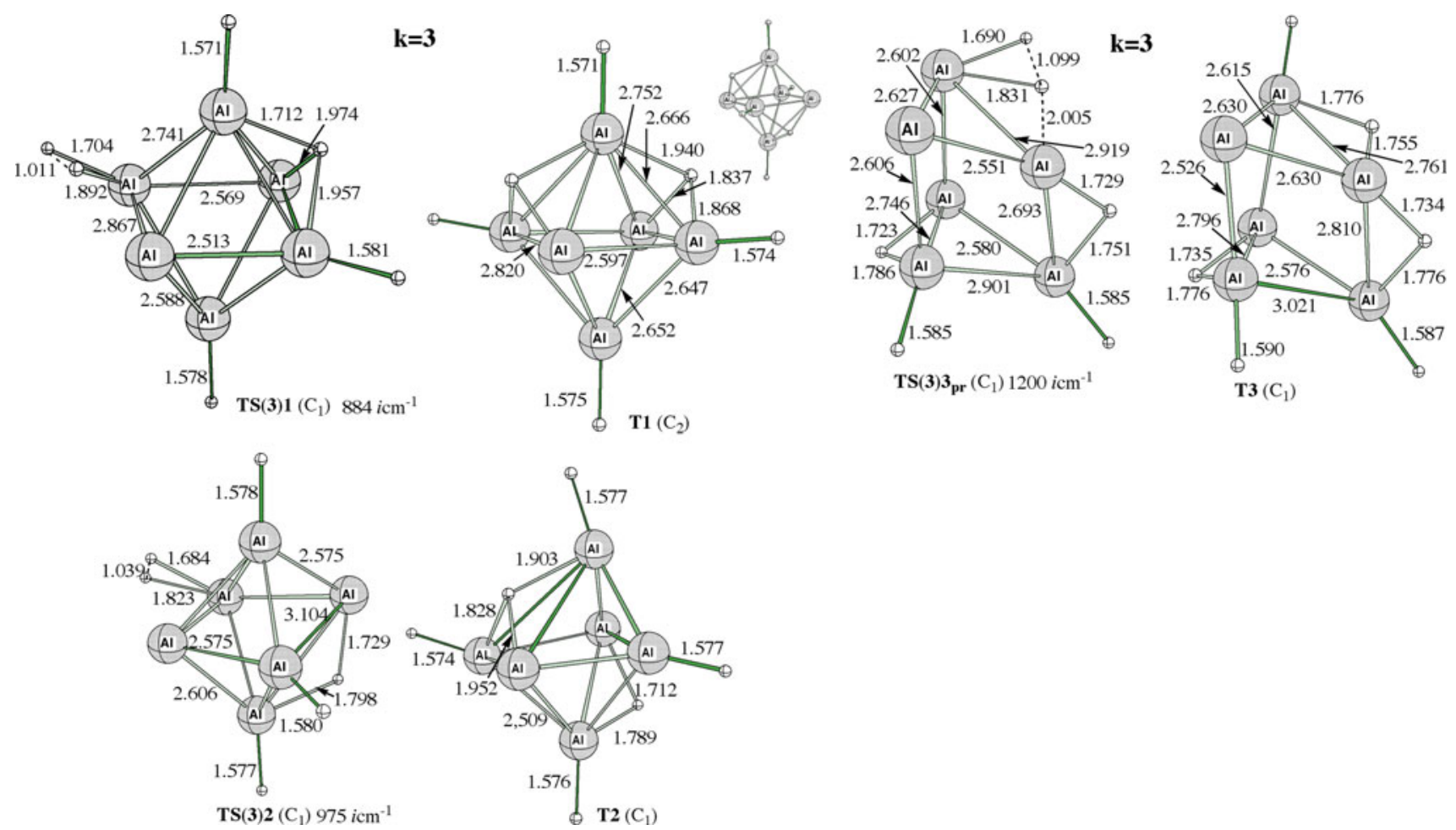

Fig. 7 Optimized geometries (B3LYP/aug-cc-pVTZ, distances in $\AA$ ) of the octahedral-TS(3)1 and TS(3)2 and prismatic-like TS(3) $\mathbf{3}_{\mathbf{p r}}$ transition states (with the imaginary frequencies) for dissociation of $\mathrm{H}_{2}$ on $\mathrm{Al}_{6} \mathrm{H}_{4}$ to yield $\mathrm{Al}_{6} \mathrm{H}_{6}$ clusters $\mathbf{T 1}, \mathbf{T} 2$ and $\mathbf{T 3}$, respectively

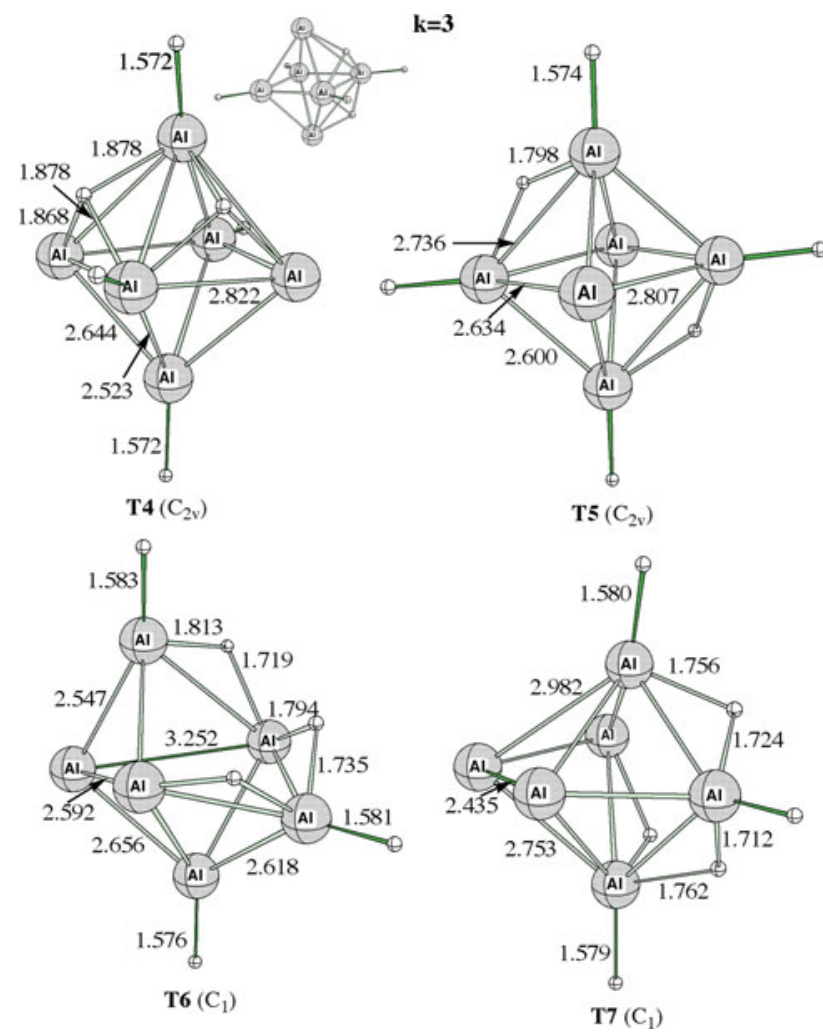

Fig. 8 Optimized geometries (B3LYP/aug-cc-pVTZ, distances in $\AA$ ) of the $\mathrm{Al}_{6} \mathrm{H}_{6}$ isomers T4-T7, including the global minimum $\mathrm{Al}_{6} \mathrm{H}_{6}$ structure (T4)
Figure 1 also shows that $\mathbf{1}$ can easily rearrange to the lower energy $\mathrm{Al}_{6} \mathrm{H}_{2}$ isomers 2 and $\mathbf{3}$ via transition states TS1-2 and TS1-3, respectively, whose B3LYP optimized structures are summarized in Fig. 2 along with those of the singlet $\mathrm{Al}_{6} \mathrm{H}_{2}$ isomers $\mathbf{4}$ and $\mathbf{1}^{\prime}$ (the triplet $\mathrm{Al}_{6} \mathrm{H}_{2}$ clusters are significantly higher in energy $[13,14])$. We note that the low-barrier isomerizations $\mathbf{1} \rightarrow \mathbf{2}$ and $\mathbf{1} \rightarrow \mathbf{3}$ involve the $\mathrm{H}$ shift from one bridging site to the other. Both the coupled cluster and G4 calculations predict the $\mathrm{Al}_{6} \mathrm{H}_{2}$ isomer 3 with the two hydrogens capping the $\mathrm{Al}-\mathrm{Al}-\mathrm{Al}$ faces which share the $\mathrm{Al}-\mathrm{Al}$ edge to be of lowest energy. Because with the CCSD(T)/aug-cc-pVTZ//B3LYP/aug-cc-pVTZ energetics TS1-3 goes below 1, the latter may not be a true minimum at the ab initio correlated level and the $\mathrm{H}_{2}$ dissociation along this $\mathrm{C}_{\mathrm{s}}$ path would result directly in $\mathbf{3}$. As can be further inferred from Fig. 1, the four di-bridged octahedral-like $\mathrm{Al}_{6} \mathrm{H}_{2}$ isomers 1-4 lie within an energy range of $3.7[3.4] / 3.1$ [3.2] $\mathrm{kcal} / \mathrm{mol}$ in terms of enthalpy/free energy at the CCSD(T)/aug-cc-pVTZ//B3LYP/aug-cc-pVTZ [G4] levels. In summary, based on the exhaustive search of the $\mathrm{Al}_{6} \mathrm{H}_{2}$ PES, we are confident that all the low-lying $\mathrm{Al}_{6} \mathrm{H}_{2}$ isomers were established, including the global minimum.

\section{$3.2 k=2$}

For the $\mathrm{Al}_{6} \mathrm{H}_{2}+\mathrm{H}_{2} \rightarrow \mathrm{Al}_{6} \mathrm{H}_{4}$ reaction, we have identified two low-barrier paths involving octahedral-like clusters 
(a)

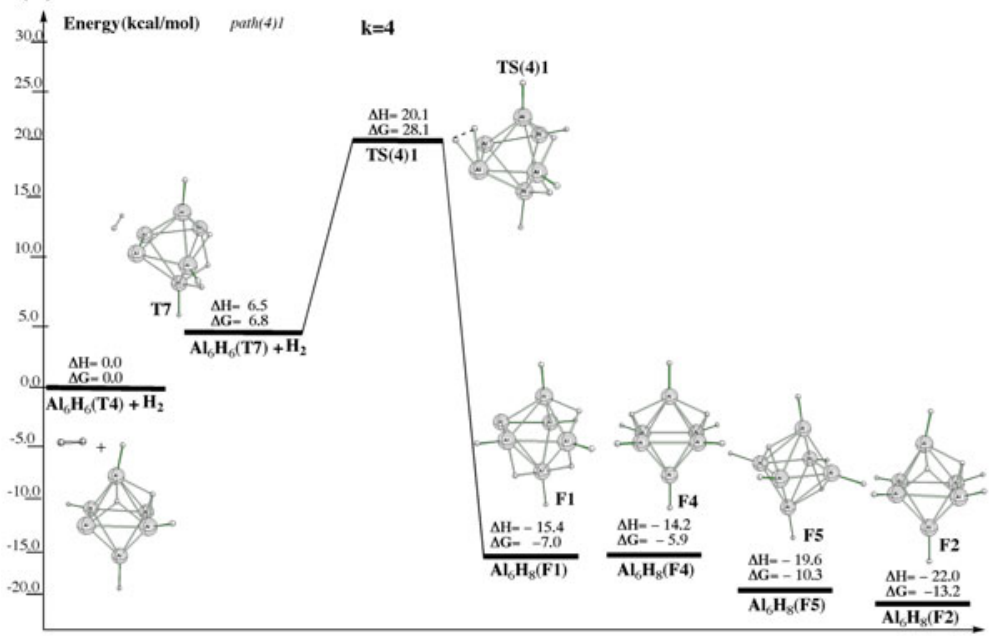

(b)

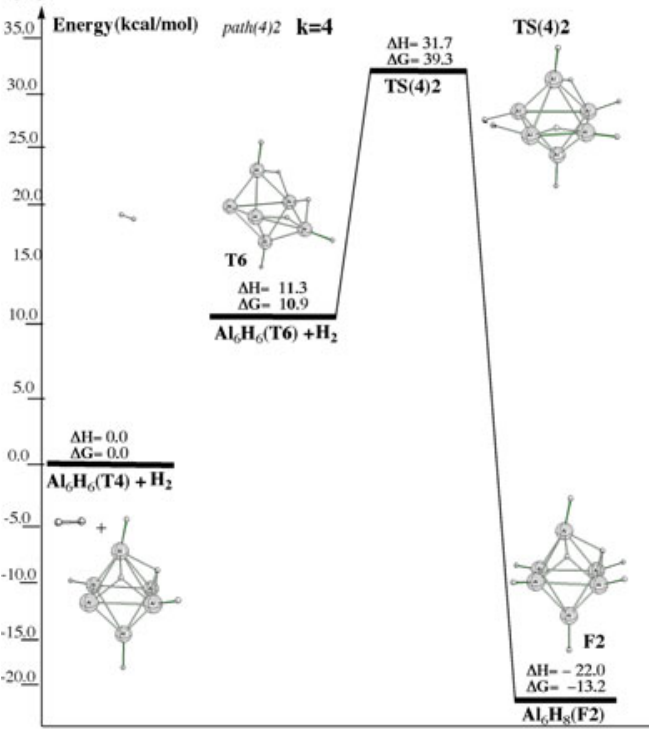

Fig. 9 Schematic enthalpy and free energy profiles (values in kcal/ mol) for dissociation of $\mathrm{H}_{2}$ on $\mathrm{Al}_{6} \mathrm{H}_{6}$ calculated at the $\mathrm{CCSD}(\mathrm{T}) /$ augcc-pVTZ//B3LYP/aug-cc-pVTZ level for the a path(4)1, b path(4)2

and another two involving trigonal prism-like species. With path(2)l (Fig. 3a), the $\mathrm{H}_{2}$ dissociation occurs via transition state $\mathbf{T S}(\mathbf{2}) \mathbf{1}$ (Fig. 4) which connects to the $\mathrm{Al}_{6} \mathrm{H}_{2}(\mathbf{1})+\mathrm{H}_{2}$ reactants and $\mathrm{Al}_{6} \mathrm{H}_{4}(\mathbf{S 1})$ product (Fig. 4). In view of the discussion in the previous section, the actual $\mathrm{Al}_{6} \mathrm{H}_{2}$ reactant of path(2)1 may be the $\mathrm{Al}_{6} \mathrm{H}_{2}(3)$ isomer. The second $\mathrm{H}_{2}$ dissociation results in forming of the new terminal and new bridging $\mathrm{Al}-\mathrm{H}$ bonds in $\mathrm{Al}_{6} \mathrm{H}_{4}(\mathbf{S 1})$ and is accompanied by the $\mathrm{H}$ shift from the bridged to the terminal site. Path(2)2 (Fig. 3b) is similar to path(2)1 because it starts with the same reactants, the hydrogen dissociation occurs on the octahedral-like metal core (via TS(2)2) and leads to the $\mathrm{Al}_{6} \mathrm{H}_{4}$ product with two terminal and two (differently) edge-bridged hydrogens, S2 (Fig. 4). (c)

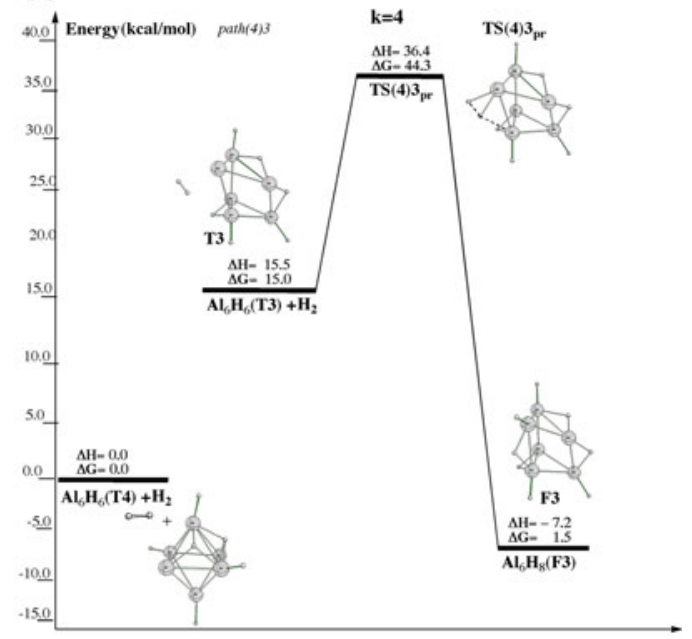

and c path(4)3. The $\Delta H$ and $\Delta G(T=298 \mathrm{~K})$ values shown are relative to the global minimum reactant asymptote $\mathrm{Al}_{6} \mathrm{H}_{6}(\mathbf{T 4})+\mathrm{H}_{2}$

The transition state $\mathbf{T S}(\mathbf{2}) \mathbf{3}$, being part of path(2)3 (Figs. 3c, 4), exhibits a heavily distorted $\mathrm{Al}_{6}$ core with two broken $\mathrm{Al}-\mathrm{Al}$ edges $(r(\mathrm{Al}-\mathrm{Al})>3.5 \AA)$. The associated IRC indicates that this TS links to the higher energy $\mathrm{Al}_{6} \mathrm{H}_{2}\left(\mathbf{1}^{\prime}\right)$ cluster comprising deformed prismatic $\mathrm{Al}_{6}$ (cf. Fig. 2) plus $\mathrm{H}_{2}$. This $\mathrm{H}_{2}$ dissociation path ends with the face- and edge-bridged $\mathbf{S 3 ~} \mathrm{Al}_{6} \mathrm{H}_{4}$ cluster with the open $\mathrm{Al}-\mathrm{Al}$ edge (Fig. 4). Finally, in the path(2)4 (Fig. 3d), the dissociative $\mathrm{H}_{2}$ addition, $\mathrm{Al}_{6} \mathrm{H}_{2}\left(\mathbf{1}^{\prime}\right)+\mathrm{H}_{2} \rightarrow \mathbf{T S}(\mathbf{2}) \mathbf{4}_{\mathbf{p r}}$ $\rightarrow \mathrm{Al}_{6} \mathrm{H}_{4}(\mathbf{S 4})$ occurs on the prism edge and requires the prior $\mathrm{Al}_{6} \mathrm{H}_{2}(\mathbf{3}) \rightarrow \mathrm{Al}_{6} \mathrm{H}_{2}\left(\mathbf{1}^{\prime}\right)$ rearrangement (not examined).

Judging both the energy barriers and exothermicity of the various second $\mathrm{H}_{2}$ dissociation modes in Fig. $3 \mathrm{a}-\mathrm{d}$, the 
Fig. 10 Optimized geometries (B3LYP/aug-cc-pVTZ, distances in $\AA$ ) of the octahedral-TS(4)1 and TS(4)2 and prismatic-like $\mathbf{T S}(\mathbf{4}) \mathbf{3}_{\mathbf{p r}}$ transition states (with the imaginary frequencies) for dissociation of $\mathrm{H}_{2}$ on $\mathrm{Al}_{6} \mathrm{H}_{6}$ to yield the $\mathrm{Al}_{6} \mathrm{H}_{8}$ clusters F1, F2 and F3, respectively. The other $\mathrm{Al}_{6} \mathrm{H}_{8}$ isomers $\mathbf{F 4}$ and $\mathbf{F 5}$ with two hydrogens capping the triangular faces are also shown; F2 is the global minimum $\mathrm{Al}_{6} \mathrm{H}_{8}$ structure

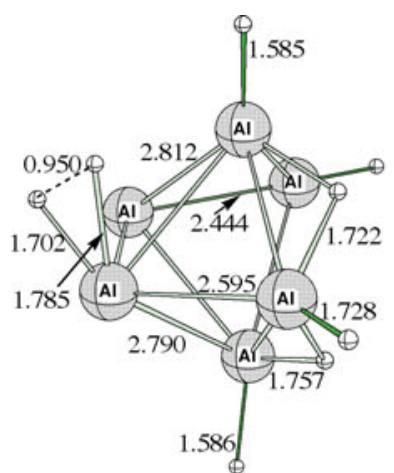

$\operatorname{TS}(4) 1\left(C_{1}\right) 475 \mathrm{icm}^{-1}$

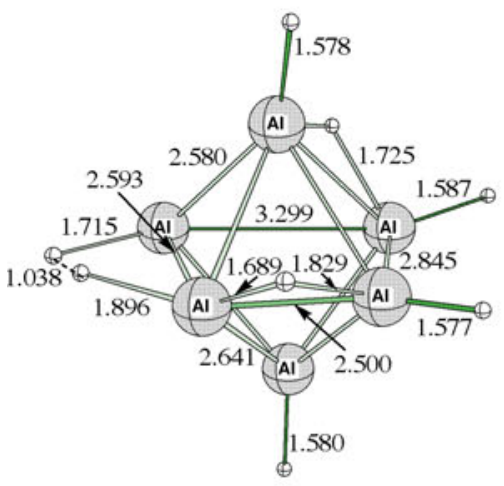

$\operatorname{TS}(4) 2\left(\mathrm{C}_{1}\right) 960 i \mathrm{~cm}^{-1}$

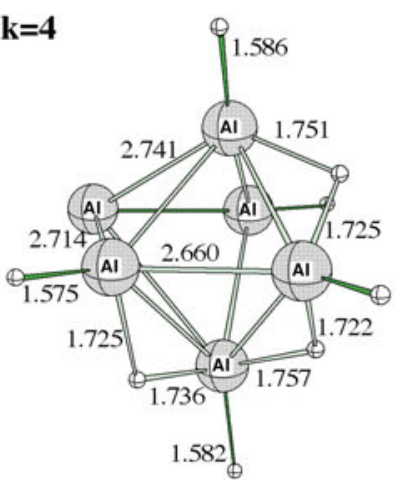

F1 $\left(\mathrm{C}_{1}\right)$

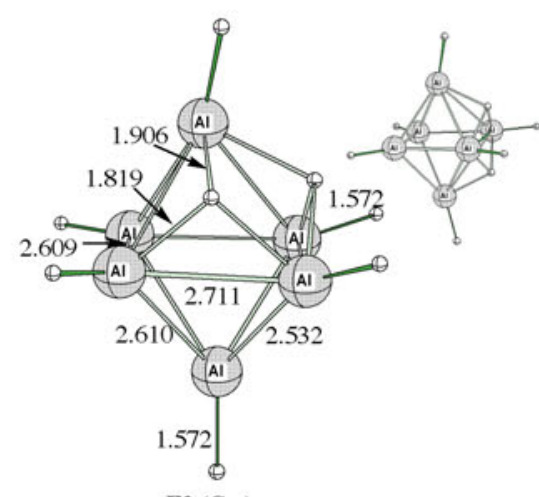

F2 $\left(\mathrm{C}_{2 v}\right)$

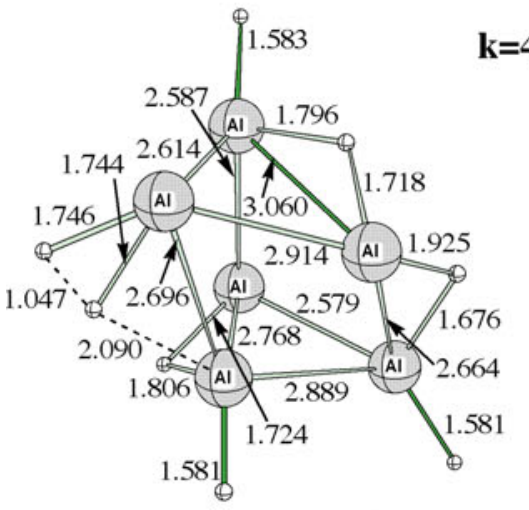

$\mathbf{T S}(\mathbf{4}) \mathbf{3}_{\mathbf{p r}}\left(\mathrm{C}_{1}\right) 1233 i \mathrm{~cm}^{-1}$

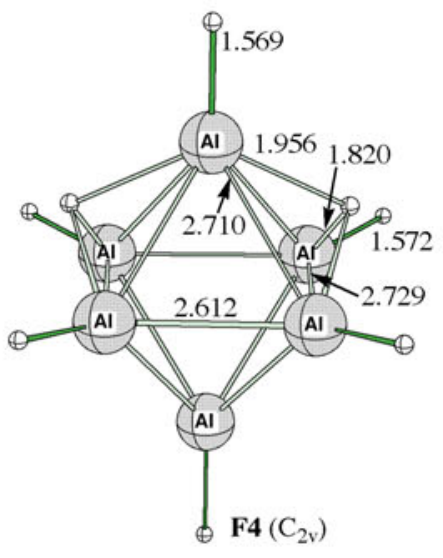

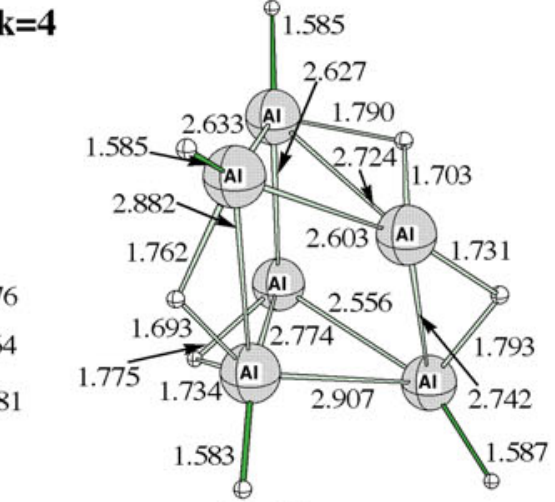

F3 $\left(\mathrm{C}_{1}\right)$

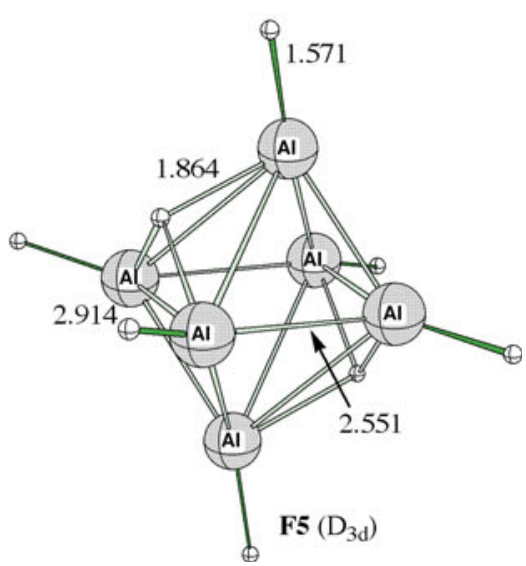


path(2)1 and path(2)2 are most favoured, with the very similar energy barriers of $15.0(22.7)$ and $12.2(20.4) \mathrm{kcal} /$ mol in $\Delta H(\Delta G)$ relative to $\mathrm{Al}_{6} \mathrm{H}_{2}(\mathbf{3})+\mathrm{H}_{2}$ (for consistency with the $k=1 \mathrm{H}_{2}$ addition, the energetics quoted for the $k=2-4$ reactions has been calculated at the $\operatorname{CCSD}(\mathrm{T}) /$ aug-cc-pVTZ//B3LYP/aug-cc-pVTZ level).

Because of the numerous minima which can exist on the $\mathrm{Al}_{6} \mathrm{H}_{4}$ PES, the kinetically most preferred modes of the second $\mathrm{H}_{2}$ dissociation indicated above were not generally expected to provide the thermodynamically most stable $\mathrm{Al}_{6} \mathrm{H}_{4}$ product. So, the extensive parallel exploration of this cluster's PES was performed at B3LYP/aug-cc-pVTZ. We have studied the $\mathrm{Al}_{6} \mathrm{H}_{4}$ structures derived from the octahedral, trigonal prismatic and capped tetragonal pyramid $\mathrm{Al}_{6}$ cores. The total 18 low-lying $\mathrm{Al}_{6} \mathrm{H}_{4}$ (distinct) isomers found S1-S18 (being within $10 \mathrm{kcal} / \mathrm{mol}$ of the global minimum) are gathered in Figure S1 of Supplementary Information. Of these, the three octahedral-based $\mathrm{Al}_{6} \mathrm{H}_{4}$ clusters S5-S7 relevant to the $k=3 \mathrm{H}_{2}$ addition step (see below), including the global minimum $\mathbf{S 5}$ are shown in Fig. 5. It is seen that in the latter $\mathrm{Al}_{6} \mathrm{H}_{4}$ cluster both

(a) Reaction barrier of $\mathrm{Al}_{6} \mathrm{H}_{2 \mathrm{k}-2}+\mathrm{H}_{2} \longrightarrow \mathrm{Al}_{6} \mathrm{H}_{2 \mathrm{k}}$

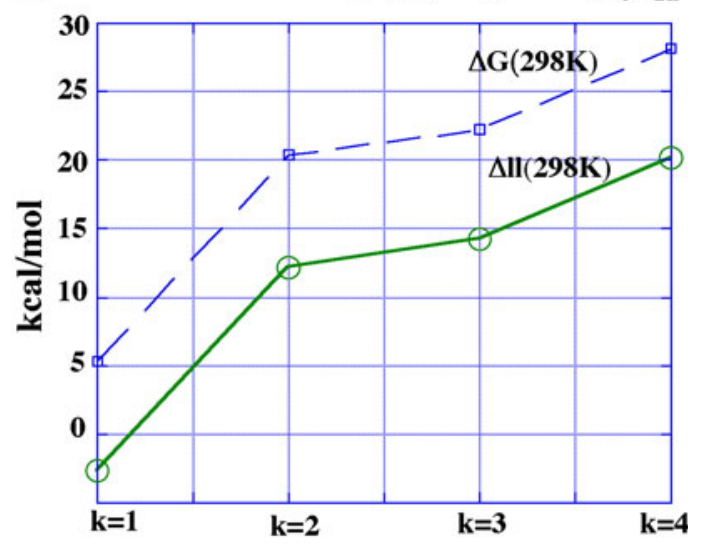

(b) Reaction energy of $\mathrm{Al}_{6} \mathrm{H}_{2 \mathrm{k}-2}+\mathrm{H}_{2} \longrightarrow \mathrm{Al}_{6} \mathrm{H}_{2 \mathrm{k}}$

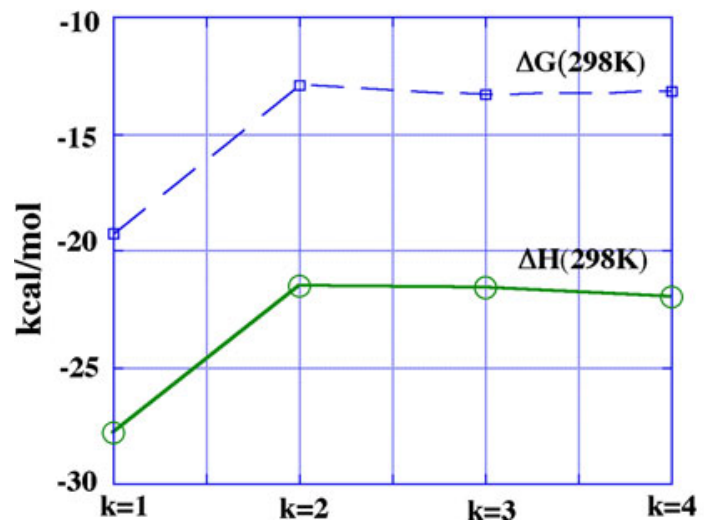

Fig. 11 Plots of the a enthalpy and free energy barriers and b enthalpies and free energies of the reactions $\mathrm{Al}_{6} \mathrm{H}_{2}$ ${ }_{k}-2+\mathrm{H}_{2} \rightarrow \mathrm{Al}_{6} \mathrm{H}_{2 k}(k=1-4)$ versus $k$ bridging hydrogens occupy the neighbouring threefold sites as in $\mathrm{Al}_{6} \mathrm{H}_{2}(\mathbf{3})$.

Although we have not studied the rearrangement of our most exothermic $\mathrm{Al}_{6} \mathrm{H}_{4}$ products $\mathbf{S 1}$ (path $\left.(2) 1\right)$ and $\mathbf{S 2}$ (path(2)2) to any of the low-energy S5-S7 clusters, we first note the five species lie within a narrow range of 5.1 (4.4) $\mathrm{kcal} / \mathrm{mol}$ in $\Delta H(\Delta G)$ (see Fig. 3a, b for their $\operatorname{CCSD}(\mathrm{T}) /$ aug-cc-pVTZ//B3LYP/aug-cc-pVTZ relative energies). Second, the isomerizations of this type are mostly related to the change of the H-bridging positions which are suggested to be low-barrier rearrangements, judging from those calculated for $k=1$.

\section{$3.3 k=3$}

We have predicted three low-lying paths for this case. The actual $\mathrm{Al}_{6} \mathrm{H}_{4}$ reactant of path(3)1 (Fig. 6a) and path(3)2 (Fig. 6b) is the isomer S7, lying $3 \mathrm{kcal} / \mathrm{mol}$ above the $\mathrm{Al}_{6} \mathrm{H}_{4}$ global minimum S5. The $\mathrm{H}_{2}$ dissociation along path(3)1 proceeds via $\mathbf{T S}(\mathbf{3}) \mathbf{1}$ (Fig. 7) with the energy barrier of $14.2(22.2) \mathrm{kcal} / \mathrm{mol}$ in $\Delta H(\Delta G)$ relative to the

(a) HOMO-LUMO gap of the $\mathrm{Al}_{6} \mathrm{H}_{2 \mathrm{k}-2}$ reactants

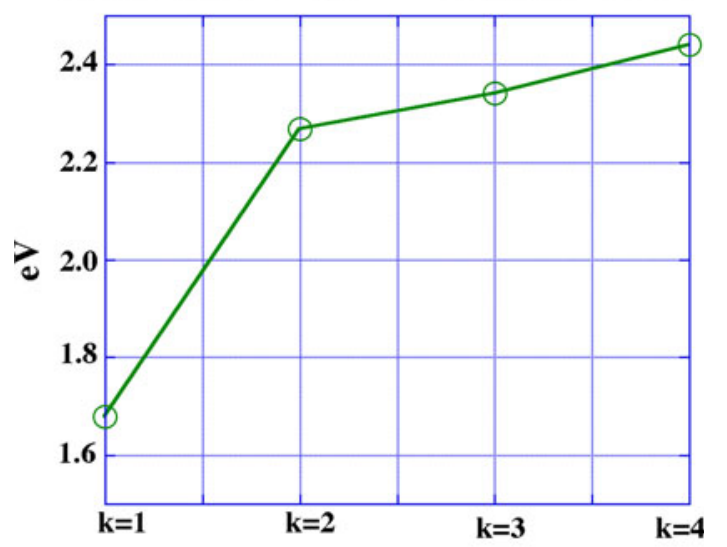

(b) HOMO-LUMO gap of the $\mathrm{Al}_{6} \mathrm{H}_{2 \mathrm{k}}$ products

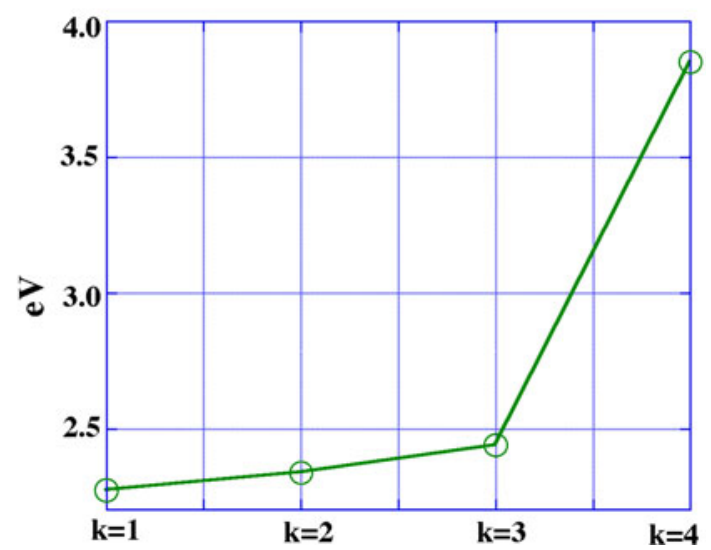

Fig. 12 A plot of the HOMO-LUMO energy gap of the most stable a $\mathrm{Al}_{6} \mathrm{H}_{2 k-2}$ and $\mathbf{b} \mathrm{Al}_{6} \mathrm{H}_{2 k}$ clusters $(k=1-4)$ versus $k$ from the B3LYP/aug-cc-pVTZ calculations 
$\mathrm{Al}_{6} \mathrm{H}_{4}(\mathbf{S 5})+\mathrm{H}_{2}$. On the product side, $\mathbf{T S}(\mathbf{3}) \mathbf{1}$ connects to the $\mathrm{Al}_{6} \mathrm{H}_{6}$ cluster $\mathbf{T 1}$ with the threefold-bridged hydrogens separated (Fig. 7). Path(3)2 involves the transition state TS(3)2 which rearranges to the $\mathrm{Al}_{6} \mathrm{H}_{6}$ isomer $\mathbf{T} 2$ with the different H-bridging pattern than T1. This mode of $\mathrm{H}_{2}$ dissociation requires, however, a higher energy barrier of 18.7 (26.1) $\mathrm{kcal} / \mathrm{mol}$ and is less exothermic compared to path(3)1.

The prismatic-like $\mathrm{Al}_{6} \mathrm{H}_{4}$ cluster $\mathbf{S 4}$, being $6 \mathrm{kcal} / \mathrm{mol}$ less stable than $\mathbf{S 5}$, and the transition state $\mathbf{T S}(\mathbf{3}) \mathbf{3}_{\mathbf{p r}}$ (Fig. 7) are engaged in path(3) 3 leading to the structurally related $\mathrm{Al}_{6} \mathrm{H}_{6}$ cluster T3 (Figs. 6c, 7). As can be inferred from Fig. $6 \mathrm{~b}-\mathrm{c}$, the path(3)2 and path(3)3 exhibit very similar energy barriers, but the latter requires additionally the $\mathrm{Al}_{6} \mathrm{H}_{4}(\mathbf{S 5}) \rightarrow \mathrm{Al}_{6} \mathrm{H}_{4}(\mathbf{S 4})$ rearrangement (not studied) and results in the higher energy $\mathrm{Al}_{6} \mathrm{H}_{6}$ product. Among the three dissociation modes examined, the path(3)1 affording T1 is thus most favoured.

Because of the numerous local minima that can appear on the $\mathrm{Al}_{6} \mathrm{H}_{6}$ PES, we anticipated that the latter path might not lead to the thermodynamically most stable $\mathrm{Al}_{6} \mathrm{H}_{6}$ product. Therefore, the extensive probe of this cluster's PES was simultaneously carried out at B3LYP/aug-cc-
pVTZ. As for $\mathrm{Al}_{6} \mathrm{H}_{4}$, we systematically investigated the $\mathrm{Al}_{6} \mathrm{H}_{6}$ structures with different $\mathrm{Al}_{6}$ cores. The outcome of this search is the total 15 distinct $\mathrm{Al}_{6} \mathrm{H}_{6}$ isomers T1-T15 (with the 12 structures being within $10 \mathrm{kcal} / \mathrm{mol}$ of the global minimum), collected in Figure S2. Of these, the five octahedral-based $\mathrm{Al}_{6} \mathrm{H}_{6}$ isomers T4-T7, including the global minimum $\mathbf{T 4}$ are shown in Fig. 8, with their CCSD(T)/aug-cc-pVTZ//B3LYP/aug-cc-pVTZ energies compared to $\mathbf{T 1}$ in Fig. 6a. In the most stable $\mathrm{Al}_{6} \mathrm{H}_{6}(\mathbf{T 4})$ structure, the two bridging hydrogens are positioned in the neighbouring threefold sites as was seen here in the lowest energy isomers of $\mathrm{Al}_{6} \mathrm{H}_{2}$ and $\mathrm{Al}_{6} \mathrm{H}_{4}$. Also, the structure of $\mathrm{Al}_{6} \mathrm{H}_{6}(\mathbf{T 4})$ is consistent with the $\mathrm{Al}_{6} \mathrm{H}_{6}$ global minimum found recently by the global-search-algorithm-for-minima approach [32].

Our energetically most favoured $\mathrm{Al}_{6} \mathrm{H}_{6}$ product T1 obtained via path(3)1 is higher in energy than $\mathbf{T} 4$ by 5.4 (5.3) $\mathrm{kcal} / \mathrm{mol}$ in $\Delta H(\Delta G)$ (Fig. 6a). We have not studied the isomerization of $\mathbf{T 1}$ to $\mathbf{T 4}$ or to the other low-energy $\mathrm{Al}_{6} \mathrm{H}_{6}$ isomers (Fig. 6a), some of which are relevant to the $k=4 \mathrm{H}_{2}$ addition step (see below). As before, we expect, however, that most of these rearrangements involving the changes of the $\mathrm{H}$-bridging positions should occur easily.

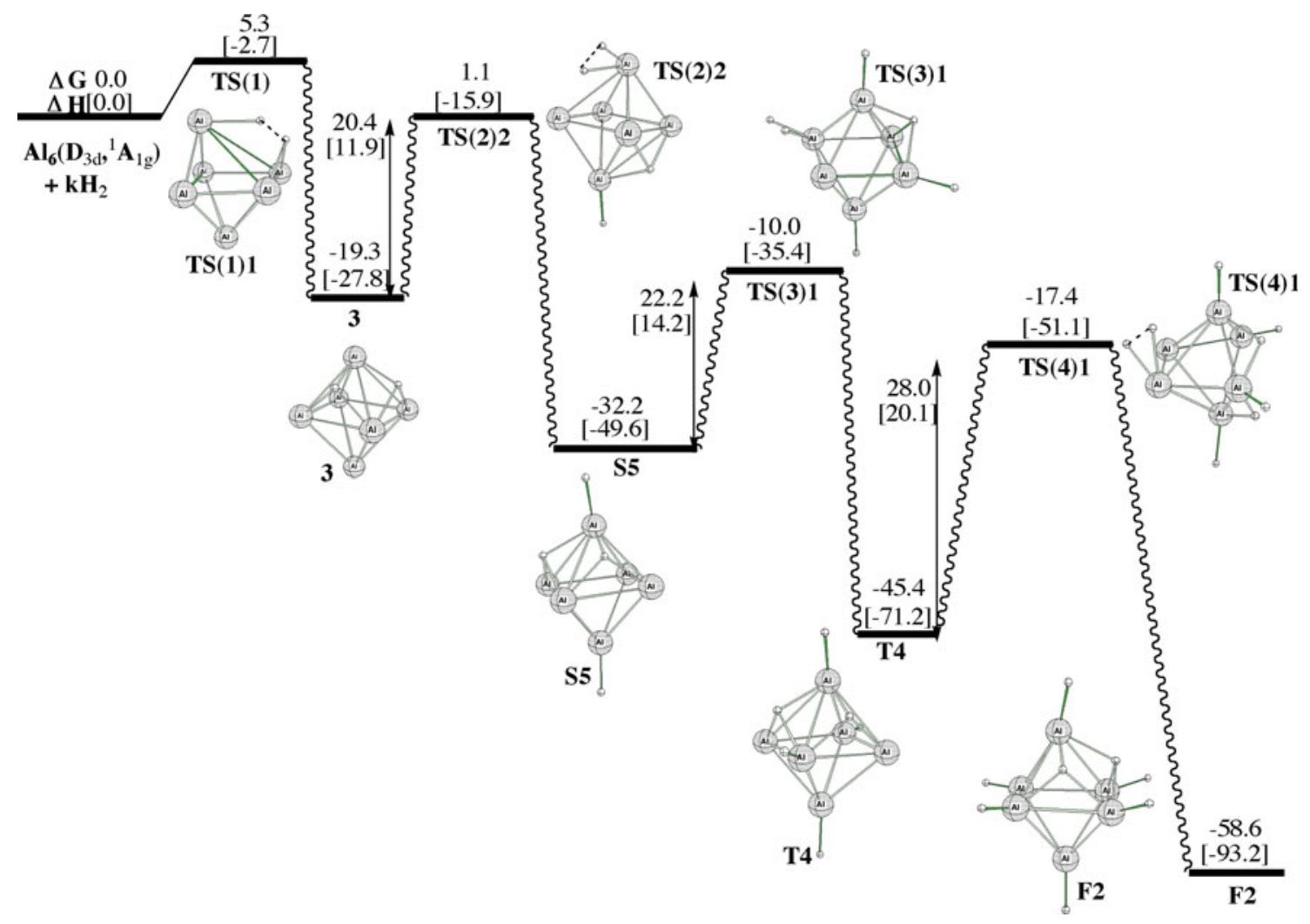

Fig. 13 Schematic free energy profile for the reaction of $\mathrm{Al}_{6}\left({ }^{1} \mathrm{~A}_{1 \mathrm{~g}}\right)$ with multiple $\mathrm{H}_{2}$ to give the 'target' $\mathrm{Al}_{6} \mathrm{H}_{8}$ alane including the lowest energy TSs for $\mathrm{H}_{2}$ dissociation on the $\mathrm{Al}_{6} \mathrm{H}_{2 k-2}$ clusters and thermodynamically most stable $\mathrm{Al}_{6} \mathrm{H}_{2 k}$ clusters calculated at the
CCSD(T)/aug-cc-pVTZ//B3LYP/aug-cc-pVTZ level. Values shown are relative free energies, with enthalpies given within square brackets (all in $\mathrm{kcal} / \mathrm{mol}$ ) 


\section{$3.4 k=4$}

The calculated routes for the fourth $\mathrm{H}_{2}$ dissociation are depicted in Fig. 9a-c. Path(4)1 involves the $\mathrm{Al}_{6} \mathrm{H}_{6}$ isomer T7 which is $7 \mathrm{kcal} / \mathrm{mol}$ less stable than the $\mathrm{Al}_{6} \mathrm{H}_{6}$ global minimum T4 (Fig. 9a). We have identified this path as kinetically most favoured with the relevant transition state TS(4)1 lying $20.1(28.1) \mathrm{kcal} / \mathrm{mol}$ in $\Delta H(\Delta G)$ above the $\mathrm{Al}_{6} \mathrm{H}_{6}(\mathbf{T 4})+\mathrm{H}_{2}$ reference. Here, $\mathrm{H}_{2}$ is cleaved on one of the 'naked' $\mathrm{Al}$ vertices of the octahedral-like metal core to yield the $\mathrm{Al}_{6} \mathrm{H}_{8}$ product F1. As seen in Fig. 10, the cluster F1 has three bridging hydrogens, and therefore is not the ground state $\mathrm{Al}_{n} \mathrm{H}_{n+2}$ alane $(n=6)$ according to the Wade's $(n+1)$ rule $[19,33,34]$.

Path(4)2 (Fig. 9b) via TS(4)2 is unique because it leads directly to the most stable $\mathrm{Al}_{6} \mathrm{H}_{8}$ product F2. This $\mathrm{H}_{2}$ dissociation involves, however, the deformed $\mathrm{Al}_{6} \mathrm{H}_{6}$ isomer T6 (being $11 \mathrm{kcal} / \mathrm{mol}$ higher in energy than T4) and significantly larger $\mathrm{H}_{2}$ dissociation barrier of 31.7 (39.3) kcal/ mol with respect to $\mathrm{Al}_{6} \mathrm{H}_{6}(\mathbf{T 4})+\mathrm{H}_{2}$. This 'on the $\mathrm{Al}-\mathrm{Al}$ edge' dissociation results in two new terminal $\mathrm{Al}-\mathrm{H}$ bonds in $\mathbf{F} 2$ cluster (Fig. 10), instead of 'the usual' terminal plus bridged bond pair. The $\mathbf{F 1} \rightarrow \mathbf{F 2}$ isomerization is suggested a more viable way of obtaining the latter $\mathrm{Al}_{6} \mathrm{H}_{8}$ cluster when starting with the former (Fig. 9a).

The different active site is seen in the transition state $\mathbf{T S}(4) \mathbf{3}_{\mathbf{p r}}$ participating in the path(4)3 (Fig. 9c), where $\mathrm{H}_{2}$ is added to the prismatic $\mathbf{T 3}$ isomer of $\mathrm{Al}_{6} \mathrm{H}_{6}$ to form the structurally related $\mathrm{Al}_{6} \mathrm{H}_{8}$ cluster $\mathbf{F 3}$ (Fig. 10). As can be inferred from Fig. 9a-c, the path ' 3 ' is clearly more energy demanding compared to ' $I$ ' and ' 2 '.

We have identified three $\mathrm{Al}_{6} \mathrm{H}_{8}$ isomers $\mathbf{F 2}\left(\mathrm{C}_{2 \mathrm{v}}\right)$, $\mathbf{F 4}\left(\mathrm{C}_{2 \mathrm{v}}\right)$ and $\mathbf{F 5}\left(\mathrm{D}_{3 \mathrm{~d}}\right)$ (Fig. 10) which could be the ground state alane $\mathrm{Al}_{n} \mathrm{H}_{n+2}(n=6)$ according to Wade's rules [19, 33, 34]. The three clusters, being within $6.6(6.2) \mathrm{kcal} / \mathrm{mol}$ in $\Delta H(\Delta G)$ (their CCSD(T)/aug-cc-pVTZ//B3LYP/aug-ccpVTZ energies are compared to F1 in Fig. 9a), adopt $n$-vertex polyhedral closo-structures with two threefold-bridged hydrogens and have $n+1=7$ skeletal bonding electron pairs. Clearly, in such cases, these rules are not sufficient to indicate the ground state isomer. The most stable $\mathrm{Al}_{6} \mathrm{H}_{8}$ isomer $\mathbf{F} 2$ is in agreement with the previous studies [21, 32] including the global-search-algorithm-for-minima approach [32]. Furthermore, consistent with the $\mathrm{Al}_{6} \mathrm{H}_{2 k}(k=1-3)$ global minima structures identified above, the $\mathrm{Al}_{6} \mathrm{H}_{8}(\mathbf{F} 2)$ cluster exhibits the same 'H-bridging motif'.
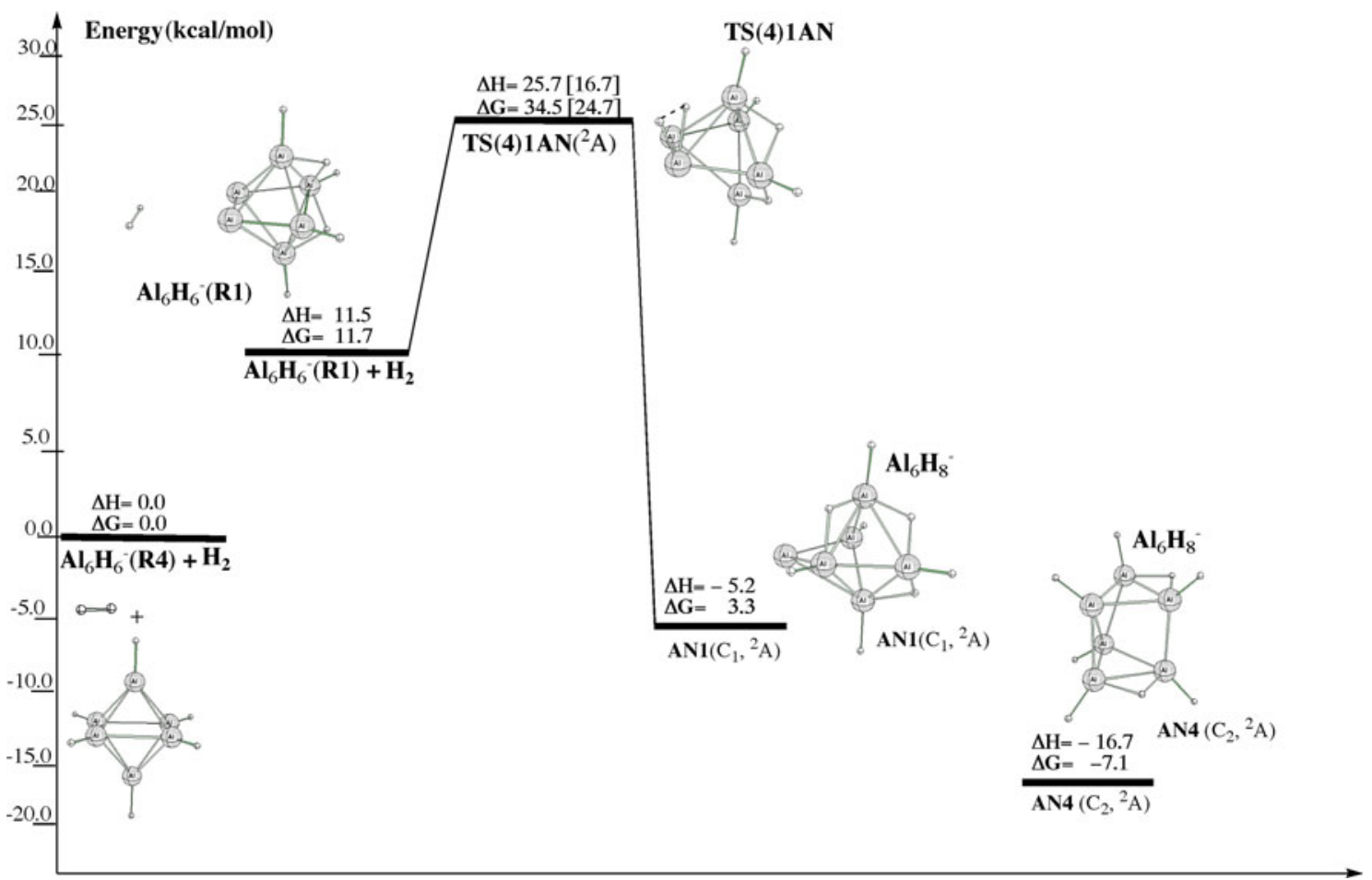

Fig. 14 Schematic enthalpy/free energy profiles (values in $\mathrm{kcal} / \mathrm{mol}$ ) for dissociation of $\mathrm{H}_{2}$ on the $\mathrm{Al}_{6} \mathrm{H}_{6}{ }^{-}$cluster anion calculated at the (U)B3LYP/aug-cc-pVTZ//(U)B3LYP/aug-cc-pVTZ level for the kinetically most favoured path. The $\Delta H$ and $\Delta G(T=298 \mathrm{~K})$ values shown are relative to the global minimum reactant asymptote $\mathrm{Al}_{6} \mathrm{H}_{6}{ }^{-}$(R4) $+\mathrm{H}_{2}$. The B3LYP/aug-cc-pVTZ//B3LYP/aug-cc-pVTZ values within square brackets refer to the neutral counterpart path(4)1 

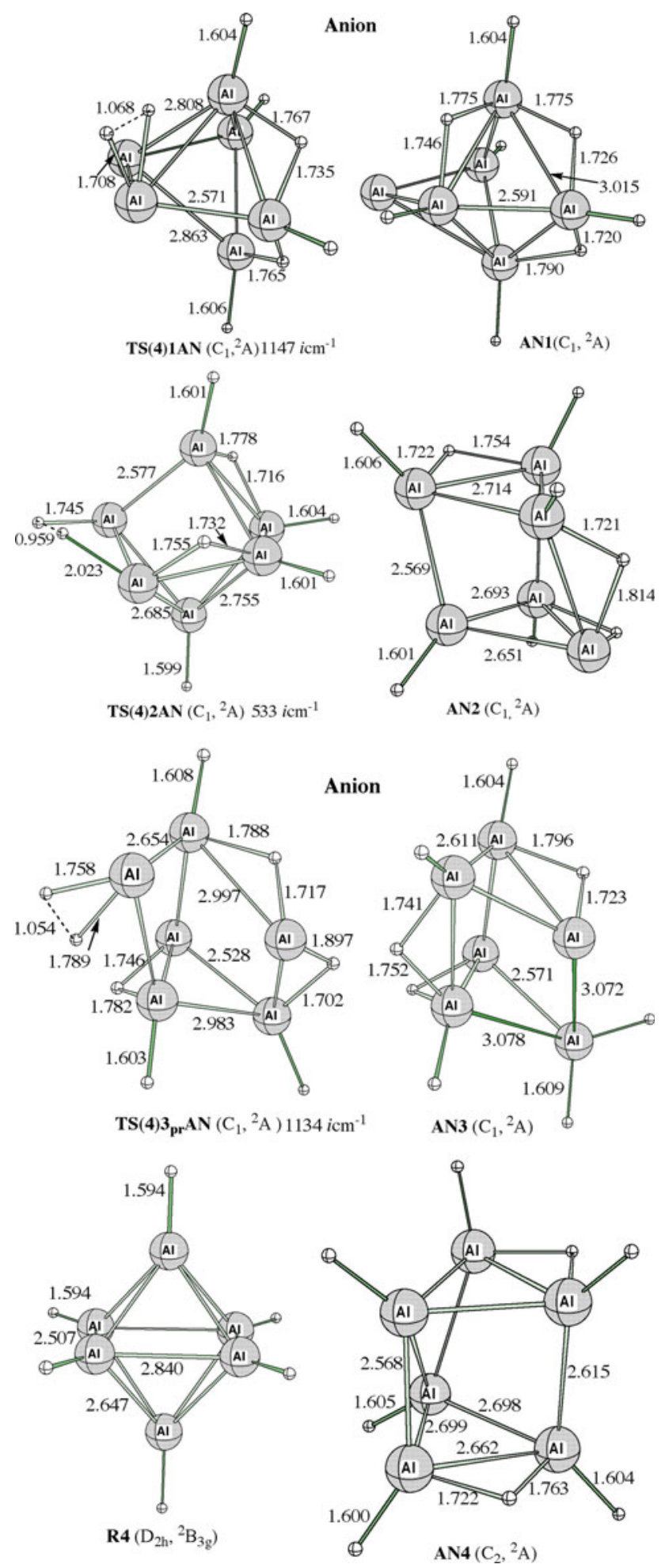

Fig. 15 Optimized geometries ((U)B3LYP/aug-cc-pVTZ, distances in $\AA$ ) of the deformed octahedral-TS(4)1AN and TS(4)2AN and prismatic-like $\mathbf{T S}(\mathbf{4}) \mathbf{3}_{\mathbf{p r}} \mathbf{A N}$ transition states (with the imaginary frequencies) for dissociation of $\mathrm{H}_{2}$ on $\mathrm{Al}_{6} \mathrm{H}_{6}{ }^{-}$to yield the $\mathrm{Al}_{6} \mathrm{H}_{8}{ }^{-}$ cluster anions AN1, AN2 and AN3, respectively. The most stable $\mathrm{Al}_{6} \mathrm{H}_{6}{ }^{-}(\mathbf{R 4})$ and $\mathrm{Al}_{6} \mathrm{H}_{8}{ }^{-}(\mathbf{A N 4})$ cluster anions are also shown
3.5 The trends in $\mathrm{H}_{2}$ activation barriers and reaction energies versus $k$

Plots in Fig. 11a, b illustrate, respectively, the barriers and energies of the reactions $\mathrm{Al}_{6} \mathrm{H}_{2 k-2}+\mathrm{H}_{2} \rightarrow \mathrm{Al}_{6} \mathrm{H}_{2 k}$ ( $k=1-4)$ versus $k$ in terms of $\Delta H$ and $\Delta G$. These profiles correspond to the lowest $\mathrm{H}_{2}$ dissociation TSs and thermodynamically most stable $\mathrm{Al}_{6} \mathrm{H}_{2 k-2}$ and $\mathrm{Al}_{6} \mathrm{H}_{2 k}$ clusters reviewed above. Figure 11a shows that the dissociation barrier increases from $k=1$ to $k=2-4$ by about $15-23 \mathrm{kcal} / \mathrm{mol}$ and that the entropy contribution $(-T \Delta S)$ to the free energy barrier is about $8 \mathrm{kcal} / \mathrm{mol}$ per $\mathrm{H}_{2}$. The barrier changes are parallelled sensibly by those of the HOMO-LUMO (H-L) gap of the $\mathrm{Al}_{6} \mathrm{H}_{2 k-2}$ reactants (in Fig. 12a).

The larger exothermic effect of formation of $\mathrm{Al}_{6} \mathrm{H}_{2}$ $(k=1$, Fig. 11b) compared to those associated with forming $\mathrm{Al}_{6} \mathrm{H}_{4}(k=2), \mathrm{Al}_{6} \mathrm{H}_{6}(k=3)$ and $\mathrm{Al}_{6} \mathrm{H}_{8}(k=4)$ can be related to the 'magic' 20 valence electron count of the first cluster [35]. Among the four product clusters, $\mathrm{Al}_{6} \mathrm{H}_{8}$ is predicted to be most stable (least reactive) as supported by its significantly larger H-L gap (in Fig. 12b) in accordance with the earlier reports [19, 20].

The 'global' free energy profile for the reaction of $\mathrm{Al}_{6}\left({ }^{1} \mathrm{~A}_{1 \mathrm{~g}}\right)$ with multiple $\mathrm{H}_{2}$ to yield the 'target' $\mathrm{Al}_{6} \mathrm{H}_{8}$ alane is given in Fig. 13. This profile which uses the lowest $\mathrm{H}_{2}$ dissociation TSs and thermodynamically most stable clusters $\mathrm{Al}_{6} \mathrm{H}_{2 k-2}$ and $\mathrm{Al}_{6} \mathrm{H}_{2 k}$ first reveals the $\Delta G$ of the overall reaction $\mathrm{Al}_{6}+4 \mathrm{H}_{2} \rightarrow \mathrm{Al}_{6} \mathrm{H}_{8}(\mathbf{F 2})$ is $-58.6 \mathrm{kcal} / \mathrm{mol}$. Second, it shows a small free energy dissociation barrier (of $1.1-5.3 \mathrm{kcal} / \mathrm{mol}$ ) for $k=1,2$, with no barrier for the addition of the third and fourth $\mathrm{H}_{2}$ due to the strongly increasing exothermicity of the total $\mathrm{Al}_{6}$ hydrogenation reaction.

\subsection{The effect of charge on the $\mathrm{H}_{2}$ dissociation}

As mentioned above, novel $\mathrm{Al}_{n} \mathrm{H}_{m}^{-}$cluster anions ( $4 \leq n \leq 8,0 \leq m \leq 10$ ) were recently generated in the gas phase $[18,19]$. Here, we have studied the effect of charge on $\mathrm{H}_{2}$ dissociation on the alanes by investigating the $\mathrm{Al}_{6} \mathrm{H}_{6}{ }^{-}+\mathrm{H}_{2} \rightarrow \mathrm{Al}_{6} \mathrm{H}_{8}{ }^{-}$reaction. The geometries of the two open-shell anions, not reported so far, were calculated by adding charge to the respective neutral clusters, followed by relaxation. The (U)B3LYP/aug-cc-pVTZ calculated structures of $\mathrm{Al}_{6} \mathrm{H}_{6}{ }^{-}(\mathbf{R} 1-\mathbf{R 1 5})$ and $\mathrm{Al}_{6} \mathrm{H}_{8}{ }^{-}$(AN1AN8) (all verified as minima) are summarized in Figures $\mathrm{S} 3$ and $\mathrm{S} 4$. The results show that the lowest energy $\mathrm{Al}_{6} \mathrm{H}_{6}{ }^{-}$ anion is octahedral-based $\mathbf{R 4}\left({ }^{2} \mathrm{~B}_{3 \mathrm{~g}}\right)$ with six terminal Hs, and the most stable $\mathrm{Al}_{6} \mathrm{H}_{8}{ }^{-}$is prism-like $\mathbf{A N} \mathbf{4}\left({ }^{2} \mathrm{~A}\right)$ with two bridging $\mathrm{Hs}$ on the opposite edges, thus differing from the most stable neutrals (see the bottom of Fig. 15). 
The energy profile of the kinetically most preferred route identified for the $\mathrm{Al}_{6} \mathrm{H}_{6}{ }^{-}+\mathrm{H}_{2} \rightarrow \mathrm{Al}_{6} \mathrm{H}_{8}{ }^{-}$reaction is depicted in Fig. 14, with the energetics calculated at the (U)B3LYP/aug-cc-pVTZ level. Here, the IRC-confirmed $\mathrm{Al}_{6} \mathrm{H}_{6}{ }^{-}$reactant is di-bridged $\mathbf{R} \mathbf{1}\left({ }^{2} \mathrm{~A}\right)$. Note that the required $\mathbf{R} 4 \rightarrow \mathbf{R} 1$ isomerization (not studied) moves $2 \mathrm{Hs}$ from the terminal to bridge sites, with the higher energy $\mathrm{Al}_{6} \mathrm{H}_{6}{ }^{-}$isomer having two 'naked' $\mathrm{Al}$ centres, thus being more reactive towards hydrogenation. The $\mathrm{H}_{2}$ dissociation transition state $\mathbf{T S}(\mathbf{4}) \mathbf{1} \mathbf{A N}\left({ }^{2} \mathrm{~A}\right)$ (Fig. 15) can be viewed the charged analogue of the neutral TS(4)1 (Fig. 10) with the more stretched $\mathrm{H}-\mathrm{H}$ bond (by $0.12 \AA$ ). Figure 14 shows that relative to the $\mathrm{Al}_{6} \mathrm{H}_{6}{ }^{-}(\mathbf{R 4})+\mathrm{H}_{2}$ reference, the $\mathrm{H}_{2}$ dissociation barrier of $25.7(34.5) \mathrm{kcal} / \mathrm{mol}$ in $\Delta H(\Delta G)$ is about $10 \mathrm{kcal} / \mathrm{mol}$ higher than that involved in the corresponding neutral path(4)1 (note that the B3LYP barriers are compared). This can be linked to the significantly higher $\mathrm{H}-\mathrm{L}$ gap of the $\mathrm{Al}_{6} \mathrm{H}_{6}{ }^{-}$anion $(3.5 \mathrm{eV})$ compared to the $\mathrm{Al}_{6} \mathrm{H}_{6}$ neutral $(2.4 \mathrm{eV})$. The transition state TS(4)1AN $\left({ }^{2} \mathrm{~A}\right)$ rearranges to the $\mathrm{Al}_{6} \mathrm{H}_{8}{ }^{-}$cluster anion AN1 $\left({ }^{2} \mathrm{~A}\right)$, which lies about $11 \mathrm{kcal} / \mathrm{mol}$ above the $\mathrm{Al}_{6} \mathrm{H}_{8}{ }^{-}$ lowest energy isomer AN4 $\left({ }^{2} \mathrm{~A}\right)$ (Fig. 14). The two kinetically less favoured routes for $\mathrm{H}_{2}$ dissociation on $\mathrm{Al}_{6} \mathrm{H}_{6}{ }^{-}$, not discussed in detail, are included in Figures S5 and S6. They can be regarded as the anion counterparts of path(4)2 and path(4)3, respectively, with the relevant anion structures displayed in Fig. 15.

A possible way of obtaining $\mathrm{Al}_{6} \mathrm{H}_{8}{ }^{-}$anion is by electron attachment to neutral $\mathrm{Al}_{6} \mathrm{H}_{8}$. In the previous section, five $\mathrm{Al}_{6} \mathrm{H}_{8}$ isomers were considered. Table $\mathrm{S} 1$ of Supplementary Information shows that an 'instantaneous' electron attachment (at the neutral's geometry) occurs easier to the prism-like form (F3) of the $\mathrm{Al}_{6} \mathrm{H}_{8}$ neutral than to its octahedral-type structures (e.g. F2) as suggested by the smaller $\mathrm{H}-\mathrm{L}$ gaps and larger vertical electron affinity of $1.50 \mathrm{eV}$ in the former case (the CCSD(T)/aug-cc-pVTZ// B3LYP/aug-cc-pVTZ value).

\section{Conclusions}

In this theoretical investigation at the B3LYP/aug-ccpVTZ and CCSD(T)/aug-cc-pVTZ//B3LYP/aug-cc-pVTZ levels, we have considered the viability of multiple $\mathrm{H}_{2}$ dissociation on the $3 \mathrm{D}$ main group 13 metal cluster $\mathrm{Al}_{6}$ to form $\mathrm{Al}_{6} \mathrm{H}_{8}$, the novel alane proposed experimentally [19]. To this end, the kinetic and thermodynamic aspects of the sequential hydrogenation of $\mathrm{Al}_{6}$ via $\mathrm{Al}_{6} \mathrm{H}_{2 k-2}+\mathrm{H}_{2} \rightarrow$ $\mathrm{Al}_{6} \mathrm{H}_{2 k}(k=1-4)$ have been studied. The minimum energy paths were generated from the located $\mathrm{H}_{2}$ dissociation transition states. Our main conclusions are as follows:

1. The $\mathrm{H}_{2}$ additions to the $\mathrm{Al}_{6} \mathrm{H}_{2 k-2}$ clusters to give the $\mathrm{Al}_{6} \mathrm{H}_{2 k}$ clusters $(k=1-4)$ are exothermic, with the enthalpy [free energy] of the overall reaction $\mathrm{Al}_{6}+4 \mathrm{H}_{2} \rightarrow \mathrm{Al}_{6} \mathrm{H}_{8}$ predicted to be $-93.2[-58.6]$ $\mathrm{kcal} / \mathrm{mol}$. The $\mathrm{Al}_{6} \mathrm{H}_{2 k}$ cluster global minima structures exhibit the same 'H-bridging motif' with two hydrogens sitting on the neighbouring threefold-bridged sites.

2. Of various $\mathrm{H}_{2}$ addition modes probed including octahedral- and trigonal prism-like clusters, those involving $\mathrm{H}_{2}$ dissociation transition states with the octahedral-like $\mathrm{Al}_{6}$ cores are found kinetically most favoured. A correlation was identified between the dissociation barriers and HOMO-LUMO gaps of the $\mathrm{Al}_{6} \mathrm{H}_{2 k-2}$ clusters versus $\mathrm{k}$.

3. For $k=1$, the $\mathrm{H}_{2}$ dissociation is predicted to have no enthalpy barrier at the $\operatorname{CCSD}(\mathrm{T}) /$ aug-cc-pVTZ// B3LYP/aug-cc-pVTZ level. A good agreement is found between the coupled cluster and G4-calculated energetics. For $k=2,3$ and 4 , the lowest enthalpic hydrogen dissociation barriers are determined to be 12 , 14 and $20 \mathrm{kcal} / \mathrm{mol}$, respectively, as measured relative to the $\mathrm{Al}_{6} \mathrm{H}_{2 k-2}$ cluster global minimum isomer plus $\mathrm{H}_{2}$ reactants. According to our calculations, the entropy contribution ( $-\mathrm{TS}$ ) to the free energy dissociation barrier is $8 \mathrm{kcal} / \mathrm{mol}$ per $\mathrm{H}_{2}$. Upon adding $\mathrm{H}_{2}$ to the $\mathrm{Al}_{6} \mathrm{H}_{2 k-2}$ cluster, the relevant van der Waals complex $\mathrm{Al}_{6} \mathrm{H}_{2 k-2} \ldots \mathrm{H}_{2}$ is first formed (at large intermolecular distances) as noticed earlier for $k=1$ $[13,14]$. These very weakly bound species were not included in the $\mathrm{H}_{2}$ dissociation reaction profiles because the focus of our study was to calculate the $\mathrm{H}_{2}$ activation barriers.

Acknowledgments The author acknowledges a generous support of computer time at the Wroclaw Center for Networking and Supercomputing, WCSS.

Open Access This article is distributed under the terms of the Creative Commons Attribution License which permits any use, distribution, and reproduction in any medium, provided the original author(s) and the source are credited.

\section{References}

1. Kubas GJ (2007) Chem Rev 107:4152

2. Knickelbein MB, Koretsky GM, Jackson KA, Pederson MD, Hajnal Z (1998) J Chem Phys 109:10692

3. Guesic ME, Morse MD, Smalley RE (1985) J Chem Phys 82:590

4. Fayet P, Kaldor A, Cox DM (1990) J Chem Phys 92:254

5. Moc J, Musaev DG, Morokuma K (2000) J Phys Chem A 104:11606

6. Lang MS, Bernhardt TM (2012) Phys Chem Chem Phys 14:9255

7. Wang X, Andrews L (2007) Angew Chem Int Ed 46:2602

8. Churchard AJ, Banach E, Borgschulte A, Caputo R, Chen J-C, Clary D, Fijalkowski KJ, Geerlings H, Genova RV, Grochala W, 
Jaron T, Juanes-Marcos JC, Kasemo B, Kroes GJ, Ljubic I, Naujoks N, Norskov JK, Olsen RA, Pendolino F, Remhof A, Románszki L, Tekin A, Vegge T, Zäch M, Züttel A (2011) Phys Chem Chem Phys 13:16955

9. Yarovsky I, Goldberg A (2005) Mol Simul 31:475

10. Jung J, Han Y-K (2006) J Chem Phys 125:064306

11. Moc J (2009) Chem Phys Lett 482:15

12. Cox DM, Trevor DJ, Whetten R, Kaldor A (1988) J Phys Chem 92:421

13. Moc J (2008) Chem Phys Lett $466: 116$

14. Pino I, Kroes GJ, van Hemert MC (2010) J Chem Phys 133:184304

15. Moc J (2005) Chem Phys Lett $401: 497$

16. Moc J (2007) Eur Phys J D 45:247

17. Dudley TC, Gordon MS (2006) Mol Phys 104:751

18. Li X, Grubisic A, Stokes ST, Cordes J, Ganteför GF, Bowen KH, Kiran B, Willis M, Jena P, Burgert R, Schnöckel H (2007) Science 315:356

19. Grubisic A, Li X, Stokes ST, Cordes J, Ganteför GF, Bowen KH, Kiran B, Jena P, Burgert R, Schnöckel H (2007) J Am Chem Soc 129:5969

20. Martinez JI, Alonso JA (2008) J Chem Phys 129:074306

21. Fu L, Xie H, Ding Y (2009) Inorg Chem 48:5370

22. Ahlrichs R, Elliott SD (1999) Phys Chem Chem Phys 1:13

23. Dunning TH (1989) J Chem Phys 90:1007

24. Becke AD (1993) J Chem Phys 98:5648

25. Lee C, Yang W, Parr RG (1988) Phys Rev B 37:785

26. Gonzalez C, Schlegel HB (1989) J Chem Phys 90:2154
27. Raghavachari K, Trucks GW, Pople JA, Head-Gordon M (1989) Chem Phys Lett 257:479

28. Curtiss LA, Redfern PC, Raghavachari K (2007) J Chem Phys 126:084108

29. Wheeler SE, Ess DH, Houk KN (2008) J Phys Chem A 112:1798

30. Curtiss LA, Redfern PC, Raghavachari K (2010) Chem Phys Lett 499:168

31. Frisch MJ, Trucks GW, Schlegel HB, Scuseria GE, Robb MA, Cheeseman JR, Scalmani G, Barone V, Mennucci B, Petersson GA, Nakatsuji H, Caricato M, Li X, Hratchian HP, Izmaylov AF, Bloino J, Zheng G, Sonnenberg JL, Hada M, Ehara M, Toyota K, Fukuda R, Hasegawa J, Ishida M, Nakajima T, Honda Y, Kitao O, Nakai H, Vreven T, Montgomery Jr JA, Peralta JE, Ogliaro F, Bearpark M, Heyd JJ, Brothers E, Kudin KN, Staroverov VN, Kobayashi R, Normand J, Raghavachari K, Rendell A, Burant JC, Iyengar SS, Tomasi J, Cossi M, Rega N, Millam NJ, Klene M, Knox JE, Cross JB, Bakken V, Adamo C, Jaramillo J, Gomperts R, Stratmann RE, Yazyev O, Austin AJ, Cammi R, Pomelli C, Ochterski JW, Martin RL, Morokuma K, Zakrzewski VG, Voth GA, Salvador P, Dannenberg JJ, Dapprich S, Daniels AD, Farkas Ö, Foresman JB, Ortiz JV, Cioslowski J, Fox DJ (2009) Gaussian 09, Revision C.01, Gaussian Inc, Wallingford

32. Marchal R, Manca G, Kahlal S, Carbonnière P, Pouchan C, Halet J-F, Saillard, J-Y (2012) Eur J Inorg Chem 2012:4856

33. Wade K (1976) Adv Inorg Chem Radiochem 18:1

34. Wade K (1971) Chem Commun 792

35. Kiran B, Jena P, Li X, Grubisic A, Stokes ST, Ganteför GF, Bowen KH, Burgert R, Schnöckel H (2007) Phys Rev Lett 98:256802 